\title{
Optimal Design of Sustainable Cellulosic Biofuel Supply Chains: Multi-objective Optimization Coupled with Life Cycle Assessment and Input-Output Analysis
}

\author{
Fengqi You, ${ }^{1,2}{ }^{*}$ Ling Tao, ${ }^{3}$ Diane J. Graziano, ${ }^{2}$ Seth W. Snyder ${ }^{2}$ \\ ${ }^{1}$ Northwestern University, 2145 Sheridan Road, Evanston, IL 60208 \\ ${ }^{2}$ Argonne National Laboratory, 9700 S. Cass Avenue, Argonne, IL 60439 \\ ${ }^{3}$ National Renewable Energy Laboratory, 1617 Cole Blvd., Golden, CO 80401
}

March 15, 2011

Submitted to AIChE Journal

\begin{abstract}
This paper addresses the optimal design and planning of cellulosic ethanol supply chains under economic, environmental, and social objectives. The economic objective is measured by the total annualized cost, the environmental objective is measured by the life cycle greenhouse gas emissions, and the social objective is measured by the number of accrued local jobs. A multiobjective mixed-integer linear programming (mo-MILP) model is developed that accounts for major characteristics of cellulosic ethanol supply chains, including supply seasonality and geographical diversity, biomass degradation, feedstock density, diverse conversion pathways and byproducts, infrastructure compatibility, demand distribution, regional economy, and government incentives. Aspen Plus models for biorefineries with different feedstocks and conversion pathways are built to provide detailed techno-economic and emission analysis results for the mo-MILP model, which simultaneously predicts optimal network design, facility location, technology selection, capital investment, production planning, inventory control, and logistics management decisions. The mo-MILP problem is solved with an $\varepsilon$-constraint method; and the resulting Pareto-optimal curves reveal the tradeoff between the economic, environmental, and social dimensions of the sustainable biofuel supply chains. The proposed approach is illustrated through two case studies for the state of Illinois.
\end{abstract}

Key words: planning, biofuel supply chain, sustainability, life cycle analysis, inputoutput analysis, multiobjective optimization

\footnotetext{
* Correspondence: Fengqi You, Northwestern University, 2145 Sheridan Road, Evanston, IL 60208. Email: you@northwestern.edu
} 


\section{Introduction}

Concerns about climate change, energy security, and the diminishing supply of fossil fuels are causing our society to search for new renewable sources of transportation fuels. Domestically available biomass has been proposed as part of the solution to our dependence on fossil fuels. Biofuels, especially the fuel ethanol produced from cellulosic materials, have the benefits of significantly reducing greenhouse gas (GHG) emissions and leading to new jobs and greater economic vitality in rural areas. ${ }^{1-2}$ In 2009 , the United States produced more than 10 billion gallons of fuel ethanol for blending with gasoline-virtually all of which was produced from corn. ${ }^{3}$ On the other hand, the Renewable Fuels Standard, part of the Energy Independence and Security Act of 2007, establishes a target of 16 billion gallons of cellulosic biofuel annual production by 2022 out of a 21 billion gallons of advanced biofuels. ${ }^{4-6}$ In observance of this mandatory production target, many new cellulosic biomass-to-biofuels supply chains will be designed and developed in the coming decade for better economic, environmental and societal performances, which are vital to the growth of the fledgling cellulosic ethanol industry. Therefore, an efficient optimization strategy is urgently needed to ensure the economic, environmental, and social viability and sustainability of the entire cellulosic ethanol supply chain at both the strategic design level and the operational planning level.

Several challenges must be faced before this goal is achieved. The first challenge is that the physical and chemical properties of the cellulosic biomass feedstocks and fuel ethanol require novel production, storage, and transportation strategies, which should be taken into account and integrated into the design and operations of the biofuel supply chains. Specifically, for cellulosic biomass feedstocks we need to account for their bulk density, deteriorating property, moisture content, supply seasonality, geographical availability, and other preprocessing and storage requirements; for biofuel products the diverse conversion pathways and byproducts and their particular requirements on transportation methods should be considered. Second, the multiscale and multisite nature of this problem requires effective temporal and spatial integration across geographically distributed facilities whose operations in the long term and the short term must be considered. A third challenge is how to quantitatively measure the economic, environmental, and social dimensions of sustainability for the entire cellulosic biofuel 
supply chain based on life cycle analysis (LCA) and economic input-output (EIO) analysis and how to incorporate the measures into the optimization framework. A fourth challenge is how to establish the tradeoff between different dimensions of sustainability and how to guarantee Pareto optimality of the competing objectives when solving the multiobjective optimization problem.

In this work, we address the optimal design and operations of cellulosic ethanol supply chains under economic, environmental, and social criteria. A mixed-integer linear programming (MILP) model is developed that takes into account the main characteristics of cellulosic ethanol supply chains, such as seasonality of feedstock supply, biomass deterioration with time, geographical diversity and availability of biomass resources, feedstock density, diverse conversion technologies and byproducts, infrastructure compatibility, demand distribution, regional economic structure, and government subsidies. Process models based on Aspen Plus for biorefineries with different feedstocks and conversion pathways are linked to the MILP model for detailed techno-economic and environmental performance analysis. The MILP optimization model integrates decision making across multiple temporal and spatial scales and simultaneously predicts the optimal network design, facility location, technology selection, capital investment, production operations, inventory control, and logistics management decisions. In addition to the economic objective of minimizing the annualized net present cost, the MILP model is integrated with LCA and regional EIO analysis through a multiobjective optimization scheme to include two other objectives: the environmental objective measured by lifecycle greenhouse gas emissions and the social objective measured by the number of accrued local jobs resulting from the construction and operation of the cellulosic biofuel supply chain. The multiobjective optimization framework allows the model to establish tradeoffs among the economic, environmental, and social performances of the cellulosic biofuel supply chains in a systematic way. The multiobjective optimization problem is solved with an $\varepsilon$-constraint method and produces Pareto-optimal curves that reveal the tradeoffs among the three objectives. The proposed optimization approach is illustrated through two case studies based on the cellulosic ethanol supply chain for the state of Illinois. County-level results for multiple supply and demand scenarios are presented that provide regionally based insight into transition pathways and consequent economic, 
environmental, and social impacts of biomass production and conversion. The scope of this work is illustrated in Figure 1.

\section{[Figure 1]}

The rest of the paper is organized as follows. We briefly review related literature in the next section. A formal problem statement along with the key assumptions is given in Section 3. The major approaches are discussed in Section 3, and the proposed optimization model is described in Section 5. In Section 6 we present computational results for case studies based on the cellulosic biofuel supply chain for the state of Illinois. Concluding remarks are presented in Section 7.

\section{Literature Review}

The papers most relevant to the problem addressed in this work are on the optimal design and operations of the process supply chain. A general review of this area is presented by Shah $^{7}$ and Papageorgiou. ${ }^{8}$ Some recent work specifically focused on biofuel supply chains is reviewed below.

Towler et al. ${ }^{9}$ presented a systemwide analysis of biomass fuels and their production infrastructure. By analyzing the relative efficiency of different farming, harvesting, and processing approaches, fuel compositions, and engine technologies, the researchers identified technologies that substantially improve the overall energy efficiency and sustainability of biomass fuels.

Dunnett et al. ${ }^{10}$ developed a multiperiod MILP modeling framework based on a statetask network representation for the simultaneous design and operational scheduling of a biomass-to-heat supply chain to minimize the total supply chain cost.

In a further work, Dunnett et al. ${ }^{11}$ presented a spatially explicit MILP model to investigate cost-optimal system configurations for a number of technological, system scale, biomass supply, and ethanol demand distribution scenarios specific to European agricultural land and population densities.

Based on the work by Dunnett et al., ${ }^{11}$ Zamboni et al. ${ }^{12}$ presented a MILP model for the strategic design of biofuel supply networks. The model takes into account the issues affecting a general biofuel supply chain simultaneously, such as agricultural practice, biomass supplier allocation, production site locations and capacity assignment, logistics 
distribution, and transport system optimization. A spatially explicit approach is used to capture the strong geographical dependence of the biomass cultivation practice performance.

Eksioglu et al. ${ }^{13}$ proposed a MILP model for the design and operations of a biomassto biorefinery supply chain. The model determines the optimal number, size, and location of biorefineries and feedstock collection as well as the amount of biomass to be processed and shipped and biomass inventory levels through a multiperiod formulation.

Huang et al. ${ }^{14}$ developed a MILP model for the multistage optimization of biofuel supply chains with the objective of evaluating the economic potential and infrastructure requirements of biofuel systems.

Mansoornejad et al. ${ }^{15}$ presented a methodology in which product portfolio design and forest biorefinery supply chain design are linked in order to build an integrated design decision-making framework through a margins-based operating policy for the biorefinery supply chain.

Following the work by Zamboni et al., ${ }^{12}$ Dal Mas et al. ${ }^{16}$ recently developed a dynamic MILP model for the optimal design and planning of biomass-based fuel supply networks according to financial criteria, taking into account uncertainty in market conditions.

Recently, Kim et al. ${ }^{17}$ proposed a MILP model for the optimal design of biorefinery supply chains. The model aims to maximize the overall profit and takes into account different types of biomass, conversion technologies, and several feedstock and plant locations. Central and distributed systems are analyzed in their work.

Another recent contribution in this area is the work by Aksoy et al. ${ }^{18}$ The authors investigated four biorefinery technologies for feedstock allocation, optimal facility location, economic feasibility, and their economic impacts in Alabama, through a MILPbased facility location model that minimizes the total transportation cost and takes into account county-level information.

Corsano et al. ${ }^{19}$ proposed an MINLP optimization model for the design and behavior analysis of sugar/ethanol supply chain. In their work, a plant performance model is integrated with the supply chain design model for simultaneous optimization, which allows the evaluation of several compromises among design and process variables. 
Akgul et al. ${ }^{20}$ recently presented a MILP model based on the one proposed by Zaboni et al. $^{12}$ for the optimal design of a bioethanol supply chain with the objective of minimizing the total supply chain cost. Their model aims to optimize the locations and scales of the bioethanol production plants, biomass and bioethanol flows between regions, and the number of transport units required for the transfer of these products between regions as well as for local delivery. The model also determines the optimal bioethanol production and biomass cultivation rates. A case study for northern Italy is presented to illustrate the applicability of the proposed model.

All these works focus on improving the economic performance of biofuel supply chains by either maximizing the profit or minimizing the cost. However, the design and operations of process supply chains may need to consider multiple performance measures and tradeoffs among conflicting goals, including environmental impacts, ${ }^{21-22}$ responsiveness, ${ }^{23-24}$ flexibility, ${ }^{25}$ and risk management. ${ }^{26-27}$ Very limited work has been directed to using multiobjective optimization for the design and operation of biofuel supply chains, and environmental emission tends to be the only criterion considered in addition to the traditional financial criteria.

Zamboni et al. ${ }^{28}$ presented a static MILP model with spatially explicit characteristics for the strategic design of a biofuel supply chain that accounts for the simultaneous minimization of the supply chain operating costs as well as the environmental impact in terms of GHG emissions.

Mele et al. ${ }^{29}$ addressed the optimal planning of supply chains for bioethanol and sugar production with economic and environmental concerns. A bicriterion MILP model is proposed for the simultaneous minimization of the total cost of a sugar/ethanol production network and its environmental performance over the entire life cycle of the sugar and ethanol.

Following the work by Mele et al., ${ }^{29}$ You and $\mathrm{Wang}^{30}$ recently addressed the life cycle optimization of biomass-to-liquids supply chain under the economic and environmental criteria. Their work shows that distributed biomass processing followed by centralized upgrading of intermediates may lead to economically viable and environmentally sustainable biofuels supply chains.

Recently, Elia et al. ${ }^{31}$ developed a MILP model that is integrated with LCA for 
determining an optimal energy-supply network based on hybrid coal, biomass, and natural gas to liquid plants using carbon-based hydrogen production.

To the best of our knowledge, none of the existing work has taken into account the economic, environmental, and social dimensions of sustainability, which is the key issue of cellulosic biofuel supply chains, and integrated all of them in a multioptimization framework. Moreover, the social impact for the design and operation of a supply chain has not been quantitatively analyzed and optimized before. An additional novelty of our work is that the proposed model takes into account most of the major characteristics of the cellulosic biofuel supply chain and is integrated with LCA, regional EIO analysis, and process modeling based on Aspen Plus.

\section{Problem Statement}

The problem addressed in this work can be formally stated as follows.

We are given a set of cellulosic biomass feedstocks that can be converted to cellulosic ethanol. These include agricultural residues (e.g., corn stover), energy crops (e.g., switchgrass), and wood residues (e.g., forest thinning). Major properties of each type of feedstock (e.g., density, degradation rate) are known. A number of conversion technologies ${ }^{32}$ exist that can be generally categorized into biochemical conversions (e.g. separate hydrolysis and fermentation, simultaneous saccharification and fermentation and consolidated bioprocessing) and thermochemical conversions (e.g., gasification followed and pyrolysis based conversions). Before the conversion, the feedstocks must be dried and may need to be stored for some time. A planning horizon of one year is divided into a number of time periods. The duration of each time period is known, and the project lifetime in terms of years is given. We assume a constant discounted rate throughout the project lifetime. The government incentives, including production and construction incentives, are known.

We are also given a cellulosic biofuel supply chain network superstructure (see Figure 2), including a set of harvesting sites and a set of demand zones, as well as the potential locations of a number of collection facilities and biorefineries. Both collection facilities and biorefineries can dry and store the feedstocks. Feedstocks can be shipped to the biorefineries directly or to the collection facilities for drying and storage before shipping 
to the biorefineries.

\section{[Figure 2]}

For each harvesting site, we are given the availability of each type of cellulosic biomass feedstock, the harvesting capacity, the percentage of harvesting loss, and the weather factor for harvesting activities in each time period. Unit cost and emission data for biomass production and harvesting are also given.

For each potential collection facility, we are given the fixed and variable cost of facility construction. The unit cost and environmental burden of biomass drying and storage are also given.

For each potential biorefinery, the costs of different technologies at different capacity levels are given. Fuel and byproducts yield, regional natural resource requirement (e.g., water consumption), operating cost, and environmental burden of biofuel production can be derived from process modeling.

For each demand zone, the biofuel demand in each time period is given, and the environmental burden associated with biofuel distribution in local region is known.

For each transportation link, the transportation capacity (in both volume and weight), available transportation modes, unit transportation cost of each mode, transportation distance, and emissions of each transportation type are known.

The objectives are to maximize the economic, environmental, and societal performances of the cellulosic biofuel supply chain by optimizing the following decision variables:

- Supply chain network structure

o Number, sizes, locations, and technology selections of the biorefineries

o Number, capacities, and locations of collection facilities

- Feedstock harvesting schedule and amount at each harvesting site

- Amount of cellulosic biomass dried and preprocessed at each collection facilities and biorefineries in each time period

- Inventory levels of cellulosic biomass and biofuel at collection facilities and biorefineries in each time period

- Ethanol yield, byproduct production amount, and feedstock and natural resource consumption rates at each biorefinery in each time period 
- Transportation amount for each transportation link and transportation mode

o Supply strategy for biomass to be delivered to production facilities

o Distribution processes for biofuel to be sent to demand zones

\section{Major Approach}

A major goal of this paper is to present a comprehensive decision support system for the design and operation of cellulosic biofuel supply chains integrating economic, environmental, and social criteria. In the following subsections, we discuss key features of this system, including the major characteristics of biofuel supply chains, the diverse conversion pathways of biofuel production, and the integration with various analysis techniques.

\section{Major characteristics of cellulosic biofuel supply chains}

A typical cellulosic biomass-to-biofuels supply chain includes five major elements: biomass production system, biomass logistics system, biofuel production system, biofuel distribution system, and biofuel end use, as shown in Figure 1..$^{5-6}$

The biomass production and logistics systems (i.e., the feedstock supply system) concentrate on the supply chain elements from the point of ground preparation and planting of biomass resources to all the biomass feedstocks ready to be utilized in the integrated biorefineries. Its major objective is to supply the integrated biorefineries with biomass feedstocks of the right specification, with the right quantity at the right time. Cellulosic biomass resources are typically geographically diverse and often seasondependent. Most cellulosic biomass resources are usually harvested at a specific time of year; the exception if perennial energy crops, such as switchgrass and miscanthus. The harvesting activities might be constrained by the harvest capacities and local weather conditions. In order to deal with the seasonality of some biomass resources, long-term storage is usually necessary. The biomass feedstocks will deteriorate over time during the storage period. Feedstocks can be stored in the collection facilities or biorefineries, but the latter have significantly higher inventory holding cost. Cellulosic materials need to be dried and preprocessed before the conversion. The drying and preprocessing can be 
performed in either the collection facilities or the biorefineries. After the drying and preprocessing, both the volume and the moisture content of the cellulosic materials will be significantly reduced. Road transportation (truck, rail, etc.) is the major method for shipping the cellulosic biomass feedstocks. Since biomass resources have relatively low transportation density, both volume and weight capacities should be considered for each transportation method, although different feedstocks can be shipped through the same transportation link. The transportation of biomass contributes significant GHG emission in the life cycle of cellulosic ethanol.

An integrated biorefinery is a facility that integrates conversion processes and equipments to produce biofuels, power, and chemicals from biomass. The main objective of integrated biorefineries is to convert the cellulosic biomass feedstocks into biofuel and byproducts. Because of the byproducts and waste treatment units, most biorefineries can be nearly self-sustaining with respect to energy consumption. A major challenge for modeling the biorefinery systems is to determine the number, size, location, and conversion technology of each biorefinery to be built, while considering the main characteristics of the feedstock supply system. Due to the inherent inefficiency of biomass growth, the biomass resources are usually bound to large areas. The decentralized nature and low transport density of biomass feedstocks put clear limits on the number, size, and locations of biorefinery plants and make biomass a typical "regional" resource, with the processing facility distributed and closed to raw material sources. A tradeoff between the advantages of larger plants and the increased costs of hauling more low-density biomass feedstocks to a processing facility over longer distances has to be established, such that the cost for feedstock and fuel transportation and the related socio-economic impact are minimized. Moreover, industrial processes that typically favor continuous production procedures in order to maximize the capital efficiency and to keep the size of installations small do not match well with the seasonal and/or discontinuous production of cellulosic biomass resources. Needed instead is either long-term storage of some cellulosic biomass feedstocks, which may deteriorate, or processes that can "digest" different feedstocks that may be harvested at different times. These two factors complicate technology development considerably and usually contribute significantly to the unit production costs of biofuels. Some production 
pathways might consume a significant amount of natural resources. For instance, producing 1 gallon of cellulosic ethanol through biochemical conversion might require 26 gallons of water. ${ }^{33-35}$ The regional availability of natural resources should be taken into account in the modeling of biorefinery production pathways. Also of note is the fact that some states in the United States provide grants for the construction or expansion of cellulosic ethanol production facilities. This fact, together with the credit from the byproducts, should be considered in the overall economic optimization.

The biofuel distribution system, which includes all the infrastructures required to transport, store, and dispense the biofuels, is used to move biofuels from biorefineries to the customer demand zones. A major issue in the cellulosic biofuel distribution system is that ethanol and gasoline-ethanol blends cannot be transported by existing pipelines that carry gasoline, because ethanol is hydrophilic and can be pulled out of the ethanolgasoline blend by the water present in petroleum pipelines. This can lead to phase separation in vehicle and poor performance. Therefore, in the near term ethanol must be transported by truck, train, or barge in an independent distribution system to ensure handling separate from the ethanol-production facility to distribution terminals, where ethanol is blended with gasoline just before delivery to retail stations by tanker trucks. This process is reasonably economical but might significantly contribute to GHG emissions. The maximum optimal distribution distance for each transportation mode should be taken into account, especially as volumes increase.

In summary, the main issues that should be considered in modeling cellulosic biofuel supply chains and the associated major characteristics are as follows:

- Feedstock availability, geographical distribution, and seasonality

- Harvesting site locations, harvest capacity, and weather variability

- Transportation network and modes, distance, and intermodal transportation

- Biomass density, transportation capacity, drying, and storage,

- Feedstock degradation

- Potential biorefinery locations, capacity, and conversion pathways

- Techno-economics, government incentives, and policy

- Regional natural resource usage and availability and regional economic structure 
- Feedstock handling and byproducts

- Demand variation and spatial distribution of customer demand zones

\section{Conversion technologies for integrated biorefineries}

Cellulosic biomass can be converted to ethanol through biochemical or thermochemical pathways. ${ }^{32}$ Typical biochemical conversion technologies include separate hydrolysis and fermentation, simultaneous saccharification and fermentation, and consolidated bioprocessing. The thermochemical pathway typically involves gasification and pyrolysis based conversions.

To optimize the entire cellulosic biofuel supply chain while taking into account the economic, environmental, and social performances of the biorefinery processes, we link the MILP supply-chain optimization model with techno-economic and environmental analysis for biorefineries with different conversion technologies and capacities. Aspen Plus process models ${ }^{36}$ are built based on the National Renewable Energy Laboratory (NREL) design reports ${ }^{37-38}$ for selected conversion pathways of cellulosic biofuel production with multiple plant capacity levels. The techno-economic and environmental analysis results of the process models are then used as inputs to the MILP optimization model for holistic cellulosic biofuel supply chain optimization. The simultaneous saccharification and fermentation technology and the thermochemical conversion method are considered in this work because the most detailed techno-economic analysis information is available. These two conversion technologies are described below.

\section{Biochemical conversion (simultaneous saccharification and fermentation)}

The biochemical design and cost estimates are based on an updated version of the NREL design report ${ }^{37}$ for conversion of corn stover to ethanol. The process design presented reflects the available estimates for performance of biochemical process with the current status of NREL research efforts. This design uses dilute acid pretreatment followed by enzymatic hydrolysis and cofermentation with recombinant Zymomonas mobilis. The corn stover is pretreated with dilute sulfuric acid $(0.5-2 \mathrm{wt} \%)$ at a high temperature $\left(140-190^{\circ} \mathrm{C}\right)$ for a short time, liberating the hemicelluloses sugars and other compounds. The pretreated biomass then goes through a solid-liquid separation step. The 
solid is washed by recycled process water and then is recombined with the liquid to the enzymatic hydrolysis. Before enzymatic hydrolysis, proper neutralization to the acid is applied, as well as conditioning. Conditioning is applied only to the liquor fraction of the pretreated biomass and not to the solids. A purchased cellulase enzyme is added to the hydrolyzate at an optimized temperature for enzyme activity. If saccharification and fermentation steps are conducted at different temperatures, a cooling step in between is required to ensure growth of the fermenting organism Z. mobilis at optimum anaerobic condition. The fermentation of the recombinant bacterium is used to coferment sugars simultaneously to ethanol. In this design, minor sugars are assumed to be fermentable. Typically, 3 to 7 days are required to convert most of the cellulose and xylose to ethanol. The "beer" liquor with $4-8 \mathrm{wt} \%$ of ethanol is then sent to a recovery and purification area, where distillation columns, a vapor phase molecular sieve adsorption unit, and water evaporation units are used. Although ethanol recovery is an energy-intensive operation, the temperature gradient from the first distillation column (beer column) can be used as a driving force for energy intensification in the entire area. Recycled water streams with reasonable levels of impurities are introduced into different areas such as pretreatment or solids washing, in order to optimize the water and steam usage. The solids from distillation (largely lignin), the concentrated syrup from the evaporator, and the biogas from anaerobic digestion are combusted in a fluidized bed combustor to produce highpressure steam for electricity credits and process heat. Excess electricity is credited as byproduct values in the cost analysis.

[Figure 3] $]^{39}$

\section{Thermochemical conversion (gasification)}

The thermochemical conversion technology (see Figure 4) uses wood chips for ethanol and other higher alcohols though a series of solid-phase and gas-phase reactions, based on the NREL design report. ${ }^{38}$ Wood chips are screened, milled, and dried before charging into the gasifier. The gasifier discussed in this work is a circulating fluidized bed indirect gasification system, with heat supplied by circulation of hot sand (olivine) between the gasifier and the char combustor. Direct steam is also injected to supply additional energy and to aid in stabilizing the biomass and sand. The gasifier converts biomass into a mixture of syngas, (composed primarily of $\mathrm{CO}, \mathrm{H}_{2}, \mathrm{CO}_{2}, \mathrm{CH}_{4}$ ), tars, and a 
solid "char", composed of residual biomass and carbon deposits. After separation by cyclones, the char is further converted to syngas by the char combustor, while the hot sand is mostly recycled. The tars are reformed into useful syngas by a fluidizable tarreforming catalyst by the tar reformer (shown in Figure 4). The deactivated reforming catalyst is separated from the effluent syngas and regenerated online similarly to catalytic cracking technology used in petroleum refining. The hot syngas is cooled through a series of heat exchange and water scrubbing steps. Then the scrubber is used to remove impurities such as particulates, ammonia along with any residual tars. This scrubber water is sent to a wastewater treatment facility. The cooled syngas is sent to an amine unit to remove $\mathrm{CO}_{2}$ and $\mathrm{H}_{2} \mathrm{~S}$. The $\mathrm{CO}_{2}$ is vented to the atmosphere, while the $\mathrm{H}_{2} \mathrm{~S}$ is reduced to its elemental form by using a Klaus-like unit called LO-CAT in this process. The cleaned and conditioned syngas is further compressed to the required synthesis pressure and is converted to mixed alcohol through a fixed-bed reactor using molybdenum sulfide-based catalyst. After the mixed alcohol synthesis step, the alcohols are separated from the unconverted syngas by condensation. The unconverted syngas is recycled to feed to the tar reformer in this design, but is optional to be recycled to the mixed alcohol synthesis reactor. After dehydration, the condensed alcohols are separated to methanol, ethanol and mixed alcohols $(\mathrm{C} 3+)$ by the main alcohol distillation columns. The methanol/water mixture is recycled to the synthesis reactor in order to increase ethanol and higher alcohol yields. The $\mathrm{C} 3+$ alcohols are for byproduct credits based on an assumed fuel value. In this design, energy is integrated throughout the process for power, steam, and electricity.

\section{[Figure 4] ${ }^{39}$}

\section{Integrating LCA with multi-objective optimization}

The motivation for using cellulosic ethanol is its better environmental performance compared with that of petroleum-based fuel. ${ }^{40}$ Since the activities that occur in the cellulosic biofuel supply chains can result in multiple GHG emissions, a suitable measure for environmental performance that accounts for various environmental impacts incurred in the cellulosic biofuels supply chains should be incorporated into the computational framework, in order to evaluate the design alternatives and operation activities from an environmental perspective. In this work, the environmental objective is to minimize the 
total annual GHG emissions (converting to $\mathrm{CO}_{2}$-equivalent per year); to this end, we adopt a "field-to-wheel" approach that accounts for the supply chain network operating impact on global warming over the life cycle of cellulosic ethanol.

Specifically, we adopt classical, process-based LCA techniques, following the principles and standards laid out in ISO 14040/14044LCA. LCA is a systematic, cradleto-grave process that evaluates the environmental impacts of a product, while considering all stages of its life cycle. In this paper, we combine LCA techniques with a mathematical programming approach, creating a systematic method that enables the automatic generation and assessment of process and supply chain alternatives that may lead to significant environmental and economic benefits. ${ }^{22}$ The application of this integrated approach involves four main phases of LCA as shown in Figure 5.

\section{[Figure 5]}

The first and most important phase of LCA is the goal and scope definition, in which decisions are made about the precision and the representative value of the assessment. The performance measure, which the overall environmental assessment must refer to (i.e., the functional unit of the system), needs to capture the nature of the product. In order to obtain a satisfactory estimation of the emissions, special attention must be given to the choice of the life cycle stages to be included. In this work, the $\mathrm{CO}_{2}$ emissions resulting from the combustion of the biofuel during vehicle operation are assumed to be contained in the carbon dioxide captured during feedstock biomass growth. ${ }^{40}$ Hence, the set of life cycle stages considered in evaluating "field-to-wheel" emissions of the bioethanol system are feedstock production and harvesting, feedstock drying and storage, feedstock transportation, biofuel production, and biofuel distribution, respectively.

The second phase is to analyze the life cycle inventory associated with each process included in the life cycle stages. In order to identify and quantify the emissions released to the environment from each process are identified and quantified, data from the Argonne GREET Model, ${ }^{41}$ the U.S. Life Cycle Inventory Database, ${ }^{42}$ and the Aspen Plus process models discussed in the previous section are used.

In the third phase, the information from the inventory analyses is further translated into a set of environmental impacts that can be aggregated into an environmental performance indicator. In this work, emissions of three $\mathrm{GHG}$ gases- $\mathrm{CO}_{2}, \mathrm{CH}_{4}$, and 
$\mathrm{NO}_{\mathrm{x}}$ - are grouped together in a single indicator in terms of carbon dioxide-equivalent emissions $\left(\mathrm{CO}_{2}\right.$-equiv/year), which is based on the concept of one hundred year global warming potentials as specified by the International Panel on Climate Change. We note that other environmental impact indicators, such as eco-indicator $99,{ }^{43}$ can also be used in the proposed framework.

In the fourth phase, the results are analyzed, and a set of conclusions or recommendations for the system is formulated. The goal of LCA is to provide criteria and quantitative measures for comparing different supply chain operation and design alternatives. One of the main shortcomings of LCA is that it does not include a systematic way of generating such alternatives and identifying the best ones in terms of environmental performance. To circumvent these limitations, we follow an integrated approach that incorporates the impact assessment results into a multi-objective optimization framework to assess diverse process alternatives that may be implemented to achieve improvement of environmental performance (e.g. GHG emissions).

Thus, in our work the preferences are articulated in the postoptimal analysis of the Pareto-optimal solutions (see Figure 5). For instance, if the two objectives are to minimize the total cost and to minimize the environmental impact, the optimal solutions will yield a Pareto curve. All the optimal solutions taking into account the economics and environmental impacts are on the Pareto curve. All the solutions above this curve (such as from point $A$ to point $B$ and from point $A$ to point $C$ in Figure 5) are suboptimal solutions that can be improved by using optimization methods. Any solution below this curve is infeasible, and the associated process alternative is impossible to achieve. This approach provides further insights into the design problem and allows for a better understanding of the inherent tradeoffs between the economic and environmental objectives in the context of sustainability.

\section{Quantifying the social impacts through input-output analysis}

The most important issue in the social dimension for cellulosic biofuel supply chains is the employment effect, which can be measured by the number of accrued local jobs (full-time equivalent for a year) in a regional economy. The more local jobs that are created, the higher the social benefits a cellulosic biofuel supply chain has brought to the 
regional economy with fixed wage levels. The Jobs and Economic Development Impact (JEDI) model $^{44}$ developed at NREL was used and integrated with our proposed multiobjective optimization model to systematically evaluate the social impacts associated with the construction and operations of cellulosic biofuel supply chains in the United States for different design alternatives and operation activities. To evaluate the number of jobs that will accrue to the state (or local region) from a project, JEDI performs an input-output multiplier analysis. ${ }^{45}$

A multiplier is a simple ratio of total systemic change over the initial change resulting from a given economic activity. It provides estimates of the total impact resulting from an initial change in economic output (e.g., employment) through the implementation or termination of a project. The size of the multiplier depends on the level of local spending for a given industry, degree of sales outside the local region, industry type, and other regional considerations. Self-sufficient areas in which businesses purchase more local inputs and export greater amounts have higher multipliers. Conversely, smaller areas of concern with decreasing self-sufficiency have lower multiplier factors. Also, some industries might be much more dependent than others on the local area for materials and labor. The multipliers are estimated through economic input-output models.

Input-output models, which were originally developed to trace supply linkages in the economy, quantify the effects of change of expenditure within a regional economy in multiple industry sectors. ${ }^{45}$ Since the construction and operational phases of cellulosic biofuel systems involve the input of materials, work force labor, and goods and services from a number of sectors, the accrued jobs that are ultimately generated by expenditures of cellulosic biofuel supply chains depend on the extent to which those expenditures are spent locally and on the structure of the local economy. Consistent with the spending pattern and state specific economic structure, different expenditures support different levels of employment, income, and output. Input-output analysis can be considered as a method of evaluating and summing the impacts of a series of effects generated by input expenditure. To determine the total effect of developing a cellulosic biofuel supply chain, three separate impacts are examined: direct, indirect, and induced.

- Direct effect: the immediate (or on-site) effect created by an expenditure. For 
example, in constructing a biorefinery plant, direct effects include the on-site contractors and crews hired to construct the plant. Direct effects also include the jobs at the biorefinery plants that build the process equipment.

- Indirect effect: the increase in economic activity that occurs when contractors, vendors, or manufacturers receive payment for goods or services and in turn are able to pay others who support their business. For instance, indirect effects include the banker who finances the contractor, the accountant who keeps the contractor's books, and the steel mills and electrical manufacturers and other suppliers that provide the necessary materials.

- Induced effect: the change in wealth that occurs or is induced by the spending of those persons directly and indirectly employed by the project.

The total effect from a single expenditure can be calculated by summing all three effects, using regional-specific (state-specific) multipliers and personal expenditure patterns. These state-by-state multipliers for employment, economic activity, and personal expenditure patterns were derived from the IMPLAN Professional model using 2002 state data. ${ }^{46}$ The changes in employment brought about by investments in the design and operations of cellulosic biofuel supply chains were matched with their appropriate multipliers for each industry sector affected by the change in employment. Both one-time impacts resulting from the construction phase and the annual impacts resulting from the annual operations were considered in the measure of social impacts. The total social benefit of a cellulosic biofuel supply chain in terms of employment is the summation of all the full-time equivalent yearly jobs created throughout the project lifetime. For example, if a cellulosic ethanol supply chain, which has a lifetime of 20 years, supports 70 local jobs (full-time equivalent for a year) in the construction phases and 18 local jobs once it is up and running, then its total social benefits can be quantified by 430 local jobs (full-time equivalent for a year).

\section{MILP Model Formulation}

We develop a multiobjective, multiperiod MILP model for the problem addressed in this work. Constraints (1)-(26) model the cellulosic biofuel supply chains and take into account their major characteristics (Section 5.1). Constraints (27)-(40) are for the capital 
and operational costs of the cellulosic biofuel supply chains; the economic objective is defined in (41) (Section 5.2). The environmental objective, which is modeled based on the LCA principles, is defined in (42) (Section 5.3). Equation (43) defines the number of regionally accrued full-time equivalent yearly jobs, which is the social objective based on EIO analysis (Section 5.4). A list of indices, sets, parameters, and variables is given in the Nomenclature section preceding the References at the end of the paper.

\section{Constraints}

\section{Biomass feedstock supply system}

The total amount of cellulosic biomass type $b$ harvested from site $i$ in time period $t$ $\left(\operatorname{harv}_{b, i, t}\right)$ should not exceed its available amount $\left(B A_{b, i, t}\right)$ in terms of dry weight.

$$
\operatorname{harv}_{b, i, t} \leq B A_{b, i, t}, \quad \forall b \in B, i \in I, t \in T .
$$

where $B A_{b, i, t}$ is the available amount of biomass type $b$ in harvesting site $i$ at time period $t$. We note that the seasonality, harvesting windows and geographical availability of different biomass feedstocks can be taken into account through different values of the parameter $B A_{b, i, t}$ in different harvesting sites and time periods for different biomass types.

The total harvest amount is also constrained by the local weather factor and the harvesting capacity. For a harvesting site at a specific time period, the total harvesting time for all the cellulosic biomass feedstocks should not exceed the duration of that time period:

$$
\sum_{b} \frac{\operatorname{harv}_{b, i, t}}{\omega_{i, t} \cdot \operatorname{HRATE} E_{b, i, t}} \leq H_{t}, \quad \forall i \in I, t \in T,
$$

where $H R A T E_{b, i, t}$ is the harvesting capacity in dry weight of biomass type $b$ in harvesting site $i$ at time period $t, H_{t}$ is the duration of time period $t$, and $\omega_{i, t}$ is the weather factor for harvesting feedstock in site $i$ at time period $t$.

The mass balance of harvesting site $i$ at time period $t$ for cellulosic biomass type $b$ is given by the following equation:

$$
\left(1-\alpha_{b, i, t}\right) \cdot \operatorname{harv}_{b, i, t}=\sum_{j} \sum_{m} f h c_{b, i, j, m, t}+\sum_{k} \sum_{m} f h r_{b, i, k, m, t}, \forall b \in B, i \in I, t \in T,
$$

where $\alpha_{b, i, t}$ is the percentage of harvest loss of biomass type $b$ in harvesting site $i$ at time period $t, f h c_{b, i, j, m, t}$ is the amount (dry weight) of feedstock type $b$ shipped from harvesting 
site $i$ to collection facility $j$ with transportation mode $m$ in time period $t$, and $f h r_{b, i, k, m, t}$ is the amount (dry weight) of feedstock type $b$ shipped from harvesting site $i$ to biorefinery $k$ with transportation mode $m$ in time period $t$. We note that harvesting sites do not store feedstocks, so the total harvest amount, after accounting for harvesting loss, should be equal to the total amount shipped to collection facilities and biorefineries.

The mass balance for collection facilities should take into account biomass degradation during the storage period. The relationship shows that the total inflows of cellulosic biomass type $b$ in collection facility $j$ at time period $t$ plus the inventory level at the end of the previous time period after considering degradation should be equal to the total outflows plus the inventory level at the end of the time period. The mass balance is given by

$\sum_{i} \sum_{m} f h c_{b, i, j, m, t}+\left(1-\beta_{b, t}\right) \cdot b i c_{b, j, t-1}=\sum_{k} \sum_{m} f c r_{b, j, k, m, t}+b i c_{b, j, t}, \forall b \in B, j \in J, t \in T$,

where $f_{c r} r_{b, j, k, m, t}$ is the amount (dry weight) of biomass type $b$ shipped from collection facility $j$ to biorefinery $k$ with transportation mode $m$ in time period $t, b i c_{b, j, t}$ is the inventory level of biomass type $b$ in collection facility $j$ at time period $t$, and $\beta_{b, t}$ is the percentage of biomass type $b$ deteriorated in collection facility $j$ at time period $t$.

The storage capacity of collection facility $j$ in terms of volume $\left(c a p c_{j}\right)$ should be constrained by its lower and upper bounds, if the collection facility is built:

$$
P C_{j}^{L} \cdot x_{j} \leq \operatorname{capc}_{j} \leq P C_{j}^{U} \cdot x_{j}, \quad \forall j \in J,
$$

where $P C_{j}^{L}$ and $P C_{j}^{U}$ are the lower and upper bounds respectively of the capacity of collection facility $j$ if it is installed, and $x_{j}$ is a binary variable that equals to 1 if a collection facility is located at site $j$.

Since a collection facility can store multiple cellulosic biomass feedstocks, the total inventory of all the feedstocks in terms of volume should not exceed the designed storage capacity. This relationship is given by

$$
\sum_{b} \frac{b i c_{b, j, t}}{\left(1-M C D_{b}\right) \cdot B D_{b}} \leq c a p c_{j}, \quad \forall j \in J, t \in T,
$$

where $B D_{b}$ is the density of dry cellulosic biomass type $b$ and $M C D_{b}$ is the moisture content of dry biomass type $b$. 
The throughput of a collection facility is also constrained by its storage capacity. By assuming regular shipment and delivery schedule, the capacity required to handle a given amount of feedstocks is twice the average storage inventory level of the collection facility. which equals the throughput of the collection facility in terms of volume divided by its inventory turnover ratio. Thus, we have the following constraint:

$2 \sum_{b} \sum_{k} \sum_{m} \frac{f c r_{b, j, k, m, t}}{\left(1-M C D_{b}\right) \cdot B D_{b} \cdot T O R_{j}} \leq c a p c_{j}, \quad \forall j \in J$,

where $T O R_{j}$ is the inventory turnover ratio, which represents the number of times that the inventory is completely replaced in each time period. We note a stochastic inventory model $^{47-50}$ can be employed to estimate the strategic safety stock level by integrating demand and supply uncertainty with supply chain design and strategic capacity planning. Because of the complexity of stochastic inventory approach, we do not use this approach in this work.

If a collection facility $j$ is installed, the input and output transportation flows of all the feedstocks types should be constrained by both the weight and volume capacity of the transportation links; otherwise, both input and output flows should be zero. The following constraints model this relationship.

$\sum_{b} \frac{f h c_{b, i, j, m, t}}{\left(1-M C_{b}\right) \cdot B D W_{b}} \leq V C H C_{i, j, m, t} \cdot x_{j}, \quad \forall i \in I, j \in J, m \in M, t \in T$,

$\sum_{b} \frac{f h c_{b, i, j, m, t}}{1-M C_{b}} \leq W C H C_{i, j, m, t} \cdot x_{j}, \quad \forall i \in I, j \in J, m \in M, t \in T$,

$\sum_{b} \frac{f c r_{b, j, k, m, t}}{\left(1-M C D_{b}\right) \cdot B D_{b}} \leq V C C R_{j, k, m, t} \cdot x_{j}, \forall j \in J, k \in K, m \in M, t \in T$,

$\sum_{b} \frac{f c r_{b, j, k, m, t}}{1-M C D_{b}} \leq W C C R_{j, k, m, t} \cdot x_{j}, \quad \forall j \in J, k \in K, m \in M, t \in T$,

where $V C H C_{i, j, m, t}$ is the volume capacity for the transportation of feedstocks from harvesting site $i$ to collection facility $j$ with transportation mode $m$ at time period $t$, $W C H C_{i, j, m, t}$ is the corresponding weight capacity, $V C H C_{j, k, m, t}$ is the volume capacity for the transportation of biomass from collection facility $j$ to biorefinery $k$ with transportation mode $m$ at time period $t, W C H C_{j, k, m, t}$ is the corresponding weight capacity, $B D W_{b}$ is the density of wet cellulosic biomass type $b$, and $M C_{b}$ is the moisture content of cellulosic 
biomass $b$. Since the feedstocks have not been dried during the transportation from the harvesting sites to the collection facilities, we need to consider their moisture content during the transportation. The intermodal transportation of multiple feedstocks with the same transportation link is taken into account through the above constraints. ${ }^{51}$

\section{Integrated biorefineries}

The mass balance of feedstock $b$ in biorefinery $k$ at time period $t$ is given by:

$$
\begin{gathered}
\sum_{i} \sum_{m} f h r_{b, i, k, m, t}+\sum_{j} \sum_{m} f c r_{b, j, k, m, t}+\left(1-\beta_{b, t}\right) \cdot b i r_{b, k, t-1}=\sum_{q} w b_{b, k, q, t}+b i r_{b, k, t}, \\
\forall b \in B, k \in K, t \in T,
\end{gathered}
$$

where $w b_{b, k, q, t}$ is the amount of feedstock type $b$ used for the production of biofuels through technology $q$ in biorefinery $k$ at time period $t$ and $b i r_{b, k, t}$ is the inventory level of biomass type $b$ in biorefinery $k$ at time period $t$. The left-hand side of Equation (12) is the summation of the amount of feedstock type $b$ transported from all the harvesting sites and collection facilities with all the possible transportation modes and the inventory level of the previous time period after considering biomass deterioration. The right hand side of the equation is the total usage amount of this type of feedstock and its inventory at the end of this time period.

Similarly, the mass balance relationship of ethanol at biorefinery $k$ at time period $t$ is given by the following equation:

$\sum_{q} w e_{k, q, t}+e i r_{k, t-1}=\sum_{l} \sum_{m} f r b_{k, l, m, t}+e i r_{k, t}, \quad \forall k \in K, t \in T$,

where $w e_{k, q, t}$ is the amount of ethanol produced through technology $q$ in biorefinery $k$ at time period $t, e i r_{k, t}$ is the inventory level of ethanol in biorefinery $k$ at time period $t$, and $f r b_{k, l, m, t}$ is the amount of ethanol shipped from biorefinery $k$ to demand zones $l$ with transportation mode $m$ at time period $t$.

To model the selection of conversion technology and capacity level of biorefineries, we introduce a binary variable $y_{k, p, q}$ that equals 1 if biorefinery $k$ with capacity level $p$ and technology $q$ is constructed. Thus, if a biorefinery $k$ is installed, at most one type of conversion technology and a capacity level can be chosen.

$$
\sum_{p} \sum_{q} y_{k, p, q} \leq 1, \quad \forall k \in K
$$


The annual production capacity (in terms of ethanol) of the biorefinery $k\left(\operatorname{cap}_{k, q}\right)$ is further defined through the following constraints:

$$
\begin{array}{ll}
P R_{p-1, q} \cdot y_{k, p, q} \leq \operatorname{capr}_{k, p, q} \leq P R_{p, q} \cdot y_{k, p, q}, & \forall k \in K, p \in P, q \in Q, \\
\operatorname{cap}_{k, q}=\sum_{p} \operatorname{capr}_{k, p, q}, & \forall k \in K, q \in Q,
\end{array}
$$

where $P R_{p, q}$ is the upper bound of the capacity of biorefinery with capacity level $p$ and technology $q$ and $c a p r_{k, p, q}$ is an auxiliary variable for the annual production capacity (in terms of ethanol) of biorefinery $k$ with capacity level $p$ and conversion technology $q$.

The ethanol production amount in biorefinery $k$ with conversion technology $q$ at each time period $t$ should not exceed the annual production capacity $\left(\operatorname{cap}_{k, q}\right)$ times the duration of the time period $\left(H_{t}\right)$ divided by the effective production time of a year $(H Y)$. The minimum production amount at this time period is bounded by a capacity utilization percentage:

$\theta_{q} \cdot \frac{H_{t}}{H Y} \cdot \operatorname{cap}_{k, q} \leq w e_{k, q, t} \leq \frac{H_{t}}{H Y} \cdot \operatorname{cap}_{k, q}, \quad \forall k \in K, q \in Q, t \in T$,

where $\theta_{q}$ is the minimum production amount as a percentage of capacity for biorefineries with technology $q$.

Ethanol production amount at each biorefinery in each time period relates to the feedstock consumption amount through the following mass balance equation:

$$
w e_{k, q, t}=\sum_{b} \eta_{b, q} \cdot w b_{b, k, q, t}, \quad \forall k \in K, q \in Q, t \in T,
$$

where $\eta_{b, q}$ is the mass balance factor of biomass type $b$ with conversion technology $q$. We note that this equation takes into account all the cellulosic biomass that can be converted to ethanol through technology $q$.

Similarly, the production amount of byproduct $g$ relates to the feedstock consumption amount through a mass balance coefficient $\epsilon_{b, g, q}$.

$$
w b p_{g, k, t}=\sum_{b} \sum_{q} \varepsilon_{b, g, q} \cdot w b_{b, k, q, t}, \quad \forall g \in G, k \in K, t \in T
$$

The consumption of regional natural resource $r$ (e.g., water) should not exceed the available amount at biorefinery location $k$ at time period $t\left(N R_{k, r, t}\right)$. The resource availability constraint is given by 
$\sum_{b} \sum_{q} \rho_{b, q, r} \cdot w b_{b, k, q, t} \leq N R_{k, r, t}, \quad \forall k \in K, r \in R, t \in T$,

where $\rho_{b, q, r}$ is the required amount of regional natural resource $r$ for the conversion of a unit quantity of biomass type $b$ with technology $q$.

If a biorefinery is selected to be built, the amount of feedstocks transported from harvesting sites and collection facilities to this biorefinery should not exceed the volume and weight capacities of the transportation links; otherwise, the transportation amount should be zero. We note that wet biomass feedstocks, which have not been dried in either collection facilities or biorefineries, are shipped from the harvesting sites, and their moisture content and wet biomass density should be considered. The transportation capacity constraints that take into account intermodal transportation are as follows:

$\sum_{b} \frac{f h r_{b, i, k, m, t}}{\left(1-M C_{b}\right) \cdot B D W_{b}} \leq V C H R_{i, k, m, t} \cdot \sum_{p} \sum_{q} y_{k, p, q}, \forall i \in I, k \in K, m \in M, t \in T$,

$\sum_{b} \frac{f h r_{b, i, k, m, t}}{1-M C_{b}} \leq W C H R_{i, k, m, t} \cdot \sum_{p} \sum_{q} y_{k, p, q}, \forall i \in I, k \in K, m \in M, t \in T$,

$\sum_{b} \frac{f c r_{b, j, k, m, t}}{\left(1-M C D_{b}\right) \cdot B D_{b}} \leq V C C R_{j, k, m, t} \cdot \sum_{p} \sum_{q} y_{k, p, q}, \forall j \in J, k \in K, m \in M, t \in T$,

$\sum_{b} \frac{f c r_{b, j, k, m, t}}{1-M C D_{b}} \leq W C C R_{j, k, m, t} \cdot \sum_{p} \sum_{q} y_{k, p, q}, \quad \forall j \in J, k \in K, m \in M, t \in T$,

where $V C H R_{i, k, m, t}$ is the volume capacity for the transportation of feedstocks from harvesting site $i$ to biorefinery $k$ with transportation mode $m$ at time period $t, W C H R_{i, k, m, t}$ is the corresponding weight capacity, $V C C R_{j, k, m, t}$ is the volume capacity for the transportation of feedstocks from collection facility $j$ to biorefinery $k$ with transportation mode $m$ at time period $t$, and $W C C R_{j, k, m, t}$ is the corresponding weight capacity.

\section{Cellulosic biofuel distribution system}

The amount of ethanol shipped from biorefinery $k$ to demand zone $l\left(f_{r} b_{k, l, m, t}\right)$ should not exceed the weight capacity of the transportation link $\left(W C R B_{k, l, m, t}\right)$, if the biorefinery is selected to be built; otherwise, no ethanol will be transported through this link.

$$
f r b_{k, l, m, t} \leq W C R B_{k, l, m, t} \cdot \sum_{p} \sum_{q} y_{k, p, q}, \quad \forall k \in K, l \in L, m \in M, t \in T
$$


All the cellulosic ethanol transported to demand zone $l$ at time period $t$ from all the biorefineries with all the transportation modes should be able to satisfy the demand:

$\sum_{k} \sum_{m} f r b_{k, l, m, t} \geq D E M_{l, t}, \quad \forall l \in L, t \in T$,

where $D E M_{l, t}$ is the demand of ethanol at demand zones $l$ at time period $t$. The demand in each demand zone is constrained by the regulations and vehicles technologies.

\section{Economic objective - minimizing annualized total cost}

The economic objective is to minimize the total annual cost $(t c)$, including the total annualized capital cost and the annual operation cost.

The total capital cost equals the total installation costs for biorefineries $\left(\right.$ tcapr $\left._{k}\right)$ and collection facilities $\left(t c a p c_{j}\right)$ minus the government incentive for constructing biofuel production facilities $\left(\right.$ inci $\left._{k}\right)$.

The capital cost of biorefinery $k$ is expressed by an interpolated piecewise linear cost curve $^{11}$ for each capacity level:

$$
\begin{gathered}
\operatorname{tcapr}_{k}=\sum_{p} \sum_{q}\left[C R_{k, p-1, q} \cdot y_{k, p, q}+\left(\operatorname{capr}_{k, p, q}-P R_{p-1, q} \cdot y_{k, p, q}\right) \cdot\left(\frac{C R_{k, p, q}-C R_{k, p-1, q}}{P R_{p, q}-P R_{p-1, q}}\right)\right], \\
\forall k \in K
\end{gathered}
$$

where $C R_{k, p, q}$ is the investment cost of installing biorefinery $k$ with capacity level $p$ and technology $q$ and $P R_{p, q}$ is the upper bound of the capacity of biorefinery with capacity level $p$ and technology $q$. We note that $t c a p c_{j}$ equals zero if $y_{k, p, q}$ is zero, because of constraints (15) and (27).

The installation cost for collection facility $j$ is given by a cost function with fixed charge:

tcapc $_{j}=C F C_{j} \cdot x_{j}+C V C_{j} \cdot$ capc $_{j}, \quad \forall j \in J$,

where $C F C_{j}$ and $C V C_{j}$ are the associated fixed and variable costs, respectively.

If biorefinery $k$ is installed, the total construction grant from the government should not exceed a percentage $\left(I N C I P_{k}\right)$ of the plant construction cost and the maximum allowable incentive amount $\left(I N C I M_{k}\right)$; otherwise, no government incentive will be received. ${ }^{52}$ The incentive for biorefinery construction is defined by the following two constraints. 


$$
\begin{array}{ll}
\text { inci }_{k} \leq I N C I M_{k} \cdot \sum_{p} \sum_{q} y_{k, p, q}, & \forall k \in K \\
\text { inci }_{k} \leq I N C I P_{k} \cdot \text { tccap }_{k}, & \forall k \in K
\end{array}
$$

Thus, the annualized total capital cost (with construction incentives) is given by:

$$
C_{\text {capital }}=\frac{I R \cdot(1+I R)^{N Y}}{(1+I R)^{N Y}-1} \cdot\left(\sum_{j} t_{c a p c}+\sum_{k} t_{c a p r}-\sum_{k} i n c i_{k}\right)
$$

where $I R$ is the discount rate, $N Y$ is the project life time in terms of years.

The annual operational cost includes cellulosic biomass production and harvesting cost, biomass feedstock transportation cost, biomass storage cost, biomass drying and preprocessing cost, fuel production cost, ethanol inventory cost, fuel transportation and distribution cost, biofuel selling incentive and byproduct credit. The definitions of these terms are given by constraints (32)-(38).

$$
\begin{aligned}
& C_{\text {biomass harvest }}=\sum_{b} \sum_{i} \sum_{t} H R V C_{b, i, t} \cdot h a r v_{b, i, t}, \\
& C_{\text {biomass transport }}=\sum_{b} \sum_{i} \sum_{j} \sum_{m} \sum_{t}\left(D F C_{b, m}+D V C_{b, m} \cdot D S H C_{i, j, m}\right) \cdot f h c_{b, i, j, m, t} \\
&+\sum_{b} \sum_{i} \sum_{k} \sum_{m} \sum_{t}\left(D F C_{b, m}+D V C_{b, m} \cdot D S H R_{i, k, m}\right) \cdot f h r_{b, i, k, m, t}, \\
&+\sum_{b} \sum_{j} \sum_{k} \sum_{m} \sum_{t}\left(D F C_{b, m}+D V C_{b, m} \cdot D S C R_{j, k, m}\right) \cdot f c r_{b, j, k, m, t} \\
& C_{\text {biomass inventory }} \sum_{b} \sum_{j} \sum_{t} H_{t} \cdot H C B_{b, j, t} \cdot b i c_{b, j, t}+\sum_{b} \sum_{k} \sum_{t} H_{t} \cdot H R B_{b, k, t} \cdot b i r_{b, k, t}, \\
& C_{\text {biomass drying }}= \sum_{b} \sum_{i} \sum_{j} \sum_{m} \sum_{t} C B D_{b} \cdot f h c_{b, i, j, m, t}+\sum_{b} \sum_{i} \sum_{k} \sum_{m} \sum_{t} C B D_{b} \cdot f h r_{b, i, k, m, t}, \\
& C_{\text {production }}=\sum_{b} \sum_{k} \sum_{q} \sum_{t} C P D_{b, q} \cdot w b_{b, k, q, t}+\sum_{k} \sum_{p} \sum_{q} F C P D_{k, p, q} \cdot c a p r_{k, p, q}, \\
& C_{\text {ethanol inventory }}=\sum_{k} \sum_{t} H_{t} \cdot H R E_{k} \cdot e i r_{k, t}, \\
& C_{\text {ethanol transport }}=\sum_{k} \sum_{l} \sum_{m} \sum_{t}\left(D F C E_{m}+D V C E_{m} \cdot D S R B_{k, l, m}\right) \cdot f r b_{k, l, m, t}, \\
& C_{\text {vol incentive }}= \sum_{k} \sum_{l} \sum_{m} \sum_{t} I N C V O_{l} \cdot f r b_{k, l, m, t}, \\
& C_{\text {byproduct credit }}= \sum_{g} \sum_{k} \sum_{t} C B P_{g, t} \cdot w b p_{g, k, t}, \\
& \forall t \in T
\end{aligned}
$$


We note that both distance variable costs and distance fixed costs are taken into account in the feedstock and fuel ethanol transportation costs given in (33) and (38). Fuel ethanol production cost given in (36) includes both variable production cost and fixed cost related to capacity level.

Therefore, the total annualized cost is given by the following equation:

$$
\begin{aligned}
\min t c & =C_{\text {capital }}+C_{\text {biomass harvest }}+C_{\text {biomass transport }}+C_{\text {biomass inventory }}+C_{\text {biomass drying }}+C_{\text {production }}, \\
& +C_{\text {ethanol inventory }}+C_{\text {ethanol transport }}-C_{\text {vol incentive }}-C_{\text {byproduct credit }}
\end{aligned}
$$

We note that both construction incentive and volumetric incentive of selling cellulosic ethanol are taken into account in the economic objective.

\section{Environmental objective - minimizing GHG emissions ( $\mathrm{CO}_{2}$-equiv/year)}

As discussed in Section 4.3, the environmental objective is to minimize the total annual $\mathrm{CO}_{2}$-equivalent $\mathrm{GHG}$ emission (te) resulting from the operations of the cellulosic biofuel supply chains. This objective is defined as follows.

$$
\begin{aligned}
& \min \quad t e=\sum_{b} \sum_{i} \sum_{t} E H V_{b, i} \cdot \operatorname{harv}_{b, i, t} \\
& +\sum_{b} \sum_{i} \sum_{j} \sum_{m} \sum_{t}\left(\operatorname{ETRB}_{b, m} \cdot D S H C_{i, j, m}\right) \cdot f h c_{b, i, j, m, t} \\
& +\sum_{b} \sum_{i} \sum_{k} \sum_{m} \sum_{t}\left(\operatorname{ETRB}_{b, m} \cdot D S H R_{i, k, m}\right) \cdot f h r_{b, i, k, m, t} \\
& +\sum_{b} \sum_{j} \sum_{k} \sum_{m} \sum_{t}\left(\operatorname{ETRB}_{b, m} \cdot \operatorname{DSCR}_{j, k, m}\right) \cdot f c r_{b, j, k, m, t} \\
& +\sum_{b} \sum_{j} \sum_{t} E I N V_{b, t} \cdot b i c_{b, j, t}+\sum_{b} \sum_{k} \sum_{t} E I N V_{b, t} \cdot \operatorname{bir}_{b, k, t} \\
& +\sum_{b} \sum_{i} \sum_{j} \sum_{m} \sum_{t} E D R_{b} \cdot f h c_{b, i, j, m, t}+\sum_{b} \sum_{i} \sum_{k} \sum_{m} \sum_{t} E D R_{b} \cdot f h r_{b, i, k, m, t} \\
& +\sum_{b} \sum_{k} \sum_{q} \sum_{t} E P D_{b, q} \cdot w b_{b, k, q, t} \\
& +\sum_{k} \sum_{t} E I N V E \cdot e i r_{k, t} \\
& -\sum_{g} \sum_{k} \sum_{t} E B P_{g} \cdot w b p_{g, k, t} \\
& +\sum_{k} \sum_{l} \sum_{m} \sum_{t}\left(\operatorname{ETRE}_{m} \cdot \operatorname{DSRB}_{k, l, m}+E E B D_{l}\right) \cdot f_{r} b_{k, l, m, t}
\end{aligned}
$$

Here $E H V_{b, t}$ is the emission of cultivating and harvesting unit amount of biomass type $b$ 
from harvesting site $i, E D R_{b}$ is the emission of drying unit amount of biomass type $b$, $E I N V_{b, t}$ is the emission of storing unit amount of biomass type $b$ at time period $t$, EINVE is the emission of storing unit amount of ethanol, $E T R B_{b, m}$ is the emission of transporting unit amount of biomass type $b$ for unit distance with transportation mode $m, E P D_{b, q}$ is the emission of producing unit amount of biomass type $b$ with technology $q$, ETRE $E_{m}$ is the emission of transporting unit amount of ethanol for unit distance with transportation mode $m, E E B D_{l}$ is the emission of blending and distributing unit amount of in demand zone $l$, and $E B P_{g}$ is the emission credit from producing unit quantity of byproduct $g$. The values of these parameters can be obtained from the Argonne GREET Model, ${ }^{41}$ the U.S. Life Cycle Inventory Database, ${ }^{42}$ the Aspen Plus process models, and relevant literature, after grouping the GHG gases into a single indicator in terms of carbon dioxide equivalent emissions $\left(\mathrm{CO}_{2}\right.$-equiv/year).

\section{Social objective - maximizing the number of accrued local jobs (full - time equivalent for a year)}

The social objective of this model is to maximize the accrued local jobs (full-time equivalent for a year) in a regional economy throughout the lifetime of the project $(t j)$. Thus, jobs created during both the construction phase and the operational phase should be considered in this measure. Multipliers derived from the state-level input-output analysis in the IMPLAN Professional model and the JEDI model are used in the formulation of the social objective, given below. 


$$
\begin{aligned}
\min t & =\sum_{k} \sum_{p} \sum_{q} J C R_{p, q} \cdot C R_{k, p, q} \cdot y_{k, p, q} \\
& +\sum_{k} \sum_{p} \sum_{q} \frac{\left(\operatorname{capr}_{k, p, q}-P R_{p-1, q} \cdot y_{k, p, q}\right) \cdot\left(J C R_{p, q} \cdot C R_{k, p, q}-J C R_{p-1, q} \cdot C R_{k, p-1, q}\right)}{\left(P R_{p, q}-P R_{p-1, q}\right)} \\
& +\sum_{j} J F C \cdot C F C_{j} \cdot x_{j}+\sum_{j} J V C \cdot C V C_{j} \cdot c a p c_{j} \\
& +N Y \cdot \sum_{b} \sum_{t} J H V_{b} \cdot t c p h b_{b, t} \\
& +N Y \cdot \sum_{b} \sum_{m} \sum_{t} J T R B_{b, m} \cdot t c t r_{b, m, t} \\
& +N Y \cdot \sum_{b} \sum_{t} J I N V_{b} \cdot t c i n_{b, t} \\
& +N Y \cdot \sum_{b} \sum_{t} J D R_{b} \cdot t c b d_{b, t} \\
& +N Y \cdot \sum_{b} \sum_{k} \sum_{q} \sum_{t} J P D_{b, q} \cdot C P D_{b, q} \cdot w b_{b, k, q, t} \\
& +N Y \cdot \sum_{k} \sum_{p} \sum_{q} J F P D_{p, q} \cdot F C P D_{k, p, q} \cdot \operatorname{capr}_{k, p, q} \\
& +N Y \cdot \sum_{t} J I N V E \cdot t c i n e_{t} \\
& +N Y \cdot \sum_{g} \sum_{t} J B P_{g} \cdot \operatorname{tcbp}_{g, t} \\
& +N Y \cdot \sum_{m} \sum_{t} J T R E_{m} \cdot t c t r e_{m, t}
\end{aligned}
$$

Here the first two terms are for the one-year equivalent jobs created in the region during the construction phase of biorefineries, the third and fourth terms are for accrued local jobs resulting from the construction of collection facilities, and the remaining terms are for the accrued local jobs resulting from the operation of the cellulosic biofuel supply chain throughout the project lifetime $(N Y)$. Each expenditure considered in the economic objective is multiplied by the corresponding input-output multiplier for accrued local jobs (full-time equivalent for one year) to account for the social objective. We note that the unit credit from byproducts has a social impact similar to that of the unit expenditures from other economic activities, although it offsets the total cost. ${ }^{44}$ The multipliers can be derived from the IMPLAN Professional model by using 2002 state data.

\section{County-Level Case Study for the State of Illinois}

To illustrate the application of the proposed model, we consider two county-level case studies for the state of Illinois. The computational studies were performed on an 
IBM T400 laptop with Intel $2.53 \mathrm{GHz}$ CPU and 2 GB RAM. The MILP model was coded in GAMS 23.4.3 and solved with the solver CPLEX 12. The optimality tolerances were all set to $1 \%$.

\section{Input data}

In both case studies, we consider 12 time periods per year (i.e., one month as a time period) in order to investigate the impacts from the seasonality of some cellulosic biomass feedstocks.

The state of Illinois comprises 102 counties. Each county is considered as a harvesting site, a potential location of a collection facility, a possible biorefinery site location and a demand zone. In other words, the cellulosic biofuel supply chain network includes 102 harvesting sites, 102 potential collection facilities, 102 possible biorefinery site locations and 102 demand zones. The distance between each pair of counties is obtained from Google Maps ${ }^{53}$ by using the center points of the counties. Three major transportation modes (rail, large trucks, and small trucks) are considered. Cost data related to transportation are obtained from Searcy et al. ${ }^{54}$ and Mahmud and Flynn. ${ }^{55}$

The major cellulosic biomass feedstocks are of three types: agricultural residues (e.g. corn stover), energy crops (e.g., switchgrass), and wood residues (e.g., forest thinning). Their corresponding available amounts are obtained from the U.S. Department of Agriculture statistical data, ${ }^{56}$ and their spatial distributions are given in Figure 6. We note that only a certain percentage of one or all the three types of feedstocks is considered in the case studies presented in the following sections. Feedstock deterioration rate is estimated to be $0.5 \%$ per month for on-site storage, and the harvesting loss is assumed to be $5 \%$. Some agricultural residues (mainly corn stover for Illinois) can be harvested only during a few months of the year. For instance, corn stover is harvested from early September to the end of November. The harvesting cost of cellulosic biomass feedstocks is provided by Petrolia ${ }^{57}$ and Eksioglu et al. ${ }^{13}$

The demand data for the state of Illinois in each month under different scenarios are based on U.S. Energy Information Administration forecasts. ${ }^{3}$ We assume that the specific demand in each county (i.e., demand zone) is proportional to its population, the data for which can be obtained from the U.S. Census Bureau. ${ }^{58}$ The population density is also 
given in Figure 6.

\section{[Figure 6]}

As discussed in Section 4.2, two major conversion technologies are considered: the biochemical pathway of simultaneous saccharification and fermentation and the thermochemical pathway via gasification. In this work, we consider three ethanol production capacity levels, with capacities ranges of 0-45 million gallons per year (MGY), 45-100 MGY, and 100-150 MGY. The economic and environmental performances of biorefineries with these capacity levels under different conversion pathways are obtained from the Aspen Plus process model. ${ }^{36}$ Relevant results from the techno-economic and environmental analysis for the $45 \mathrm{MGY}$ biorefinery plants are listed in Tables A1-A4 of the Appendix.

Emission data related to transportation, storage, distribution, and biomass production came from the GREET Model ${ }^{41}$ developed at Argonne National Laboratory and the U.S. Life Cycle Inventory Database ${ }^{42}$ created by the National Renewable Energy Laboratory; emission data related to biofuel production are from the process models as discussed above. In addition, state-level input-output multipliers from the IMPLAN Professional model $^{46}$ and the JEDI model ${ }^{44}$ are used to quantify the accrued jobs (full-time equivalent for a year) for the state of Illinois.

\section{Case study 1: cost-effective design (near-term scenario)}

In the first case study, we consider a near-term scenario to supply $10 \%$ of the current fuel usage in Illinois (i.e., the blending requirement for E10) with cellulosic ethanol produced from all the agricultural residues produced in Illinois. Currently, almost all the ethanol in E10 in Illinois is converted from $\operatorname{corn}^{3}$; and the agricultural residues, which are mainly corn stovers for Illinois, have strong seasonality. Only the economic objective, minimizing the total annualized cost, is considered for this case. The resulting MILP problem includes 714 binary variables, 1,133,526 continuous variables, and 3,390,786 constraints. A solution within $1 \%$ optimality gap was found after 22,171 CPU seconds (around 6 hours and 10 minutes in CPU time).

\section{[Figure 7]}

The best-known minimum annualized cost (solution with $1 \%$ optimality gap) for the 
state-level supply chain is $\$ 1,863,475,059$, which implies a cellulosic ethanol unit cost of $\$ 3.663 /$ gallon. The optimal locations of the biorefineries, each plant's capacity and conversion technology, and the counties supplied by the biorefineries (if a county's demand is met by the ethanol from multiple biorefineries, it is considered in the "service zone" of its major supplier) are given in Figure 7. Four biorefineries are installed. Two of them-located in northern Illinois (Lee County and La Salle County) - supply 13 counties each and have relatively small capacities, 102 MGY and 124 MGY, respectively; the one in La Salle County refinery is a bit larger in terms of production capacity because it also partially supplies Cook County, Will County, and DuPage County in the Chicago area, with the highest population density in the state. The biorefinery located at Iroquois County has the largest capacity, $150 \mathrm{MGY}$, because it supplies most of the ethanol fuel for Chicago area. The refinery in Christian County also has a relatively large size, 138 MGY, because it supplies more than half the counties in Illinois, in central and southern Illinois. All four biorefineries are located in counties where there are abundant resources of agricultural residue, as can be seen from the map on the right of Figure 7. We note that all the biorefineries adapt the biochemical conversion technology. The main reason is that most agricultural residues in Illinois are corn stover. Simultaneous saccharifaction and fermentation, compared with the thermochemical conversion technology, is closer to commercialization and more suitable to economies of scale than thermochemical conversion technology for producing ethanol from corn stover. The locations, sizes, and technology selections of biorefinery plants reveal the tradeoffs among capital cost, production cost, and transportation cost.

\section{[Figure 8]}

Figure 8 shows the total amount of agricultural residues stored in biorefineries and collection facilities each month. We can see a strong seasonality from the chart: the total inventory level decreases from the maximum in October to the minimum in August next year. This trend is due to the harvesting season of corn stovers, which is a byproduct of corn harvesting from September to November every year. We can also observe that only about 1000 tonnes of agricultural residues are stored in September, because most agricultural residues harvested in this month are converted to ethanol, which has lower storage cost and does not deteriorate. Because of the capacity limit, however, not all the 
feedstocks harvested from September to November can be converted to ethanol. Another reason is that each biorefinery plant, once it is installed, should maintain a minimum production level. Thus, a significant proportion of the agricultural residues are stored in order to keep down the installation sizes of biorefineries and avoid supply/production disruption.

\section{[Figure 9]}

A breakdown of the total cost for this case study is given in Figure 9. We can see both capital investment and production cost represent approximately one-third of the total cost. The remaining $35 \%$ is allocated to transportation cost $(17 \%)$, feedstock cost $(10 \%)$, and storage cost $(8 \%)$. The relative low feedstock cost is because corn stover has a particular low cost in Illinois due to its abundance. The results shown in Figure 9 suggest that conversion efficiency and equipment utilization are the bottlenecks to reducing the cellulosic ethanol cost. It is therefore of great importance to develop advanced conversion processes to reduce both capital and unit production costs.

\section{Case study 2: multiobjective design (Year 2022 scenario)}

In the second case study, we consider a scenario for the year 2022, when the United States will produce/consume at least 16 billion gallons of cellulosic ethanol per year, based on the target set by the Energy Independence and Security Act of $2007 .{ }^{4,6}$ Since $5.594 \%$ of the cellulosic biomass resources in the U. S. is in the state of Illinois, ${ }^{59}$ we assume the same proportion of the 16 billion gallons of cellulosic ethanol will be produced/consumed in Illinois in the year 2022; that is, in this second case study the demand for cellulosic biofuel for the entire state is 895.04 million gallons per year. Similar to the first case study, the demand in each county is assumed to be proportional to its population, based on the data from U.S. Census $2000{ }^{58}$ From the supply side, we consider that $50 \%$ of the state's cellulosic biomass resources can be converted to ethanol. The feedstocks include not only agricultural residues (corn stover, etc.), but also energy crops (switchgrass, miscanthus, etc.) and wood residues (forest and primary mill residue, secondary mill, urban wood, etc.). We note that wood residues do not have as strong seasonality as do corn stovers. 
All three objectives for the economic, environmental, and social performances of the cellulosic biofuel supply chains are considered in this case study. The resulting multiobjective MILP problem includes 714 binary variables, 2,637,210 continuous variables, and 3,400,578 constraints.

We first consider the tradeoff between economic and environmental performances by using the $\varepsilon$-constraint method to obtain the Pareto-optimal curve. The first step of the $\varepsilon^{-}$ constraint method is to determine the optimal lower and upper bounds of the annual $\mathrm{CO}_{2}-$ equivalent GHG emission. The lower bound is obtained by minimizing (42) subject to constraints (1)-(38). To obtain the Pareto-optimal upper bound, we solve an optimization problem with constraints (1)-(42) and the following objective function:

$\min : t c+\chi \cdot t e$,

where $\chi$ is a very small value (on the order of $10^{-6}$ ). In the last step, we fix $\varepsilon$ to 20 values with identical intervals between the upper and lower bounds of the annual GHG emission and add the following constraint to the model, with the objective of minimizing (41).

te $\leq \varepsilon$

In this way we obtain an approximation of the Pareto-optimal curve for the proposed model, together with the optimal solutions for different values of GHG emissions. The entire solution process takes a total of 1,152,237 CPU-seconds (around 320 CPU-hours) for all 22 instances. The resulting Pareto curve is given in Figure 10.

\section{[Figure 10]}

All the optimal solutions that take into account the economic and environmental objectives lie on the Pareto curve. Hence, the solutions above the curve in Figure 10 are suboptimal solutions, and any solution below this curve is infeasible. We can see from Figure 10 that as the optimal total annualized cost reduces from around \$5,950 MM to around $\$ 5,350 \mathrm{MM}$, the annual $\mathrm{CO}_{2}$-equivalent $\mathrm{GHG}$ emission resulting from the operation of the cellulosic biofuel supply chain increases from around 22,300 Kton to around 23,000 Kton. The trend of this Pareto curve reveals the tradeoff between economics and environmental performances. In particular, by comparing the two solutions with red circles in Figure 10, we can identify a "good choice" solution that 
significantly reduces the GHG emissions with only a small increase over the minimum cost solution.

The optimal locations of the biorefineries, each plant's capacity and conversion technology, and the counties supplied by the biorefineries for the minimum cost solution and the "good choice" solution are given in Figure 11. We can see that the minimum cost solution, which has a ethanol supply chain cost of $\$ 3.225 /$ gallon, involves construction of six biorefineries in the Cook County (150 MGY), Will County (150 MGY), Bureau County (149 MGY), McLean County (147 MGY), Champaign County (150 MGY), and Saline County (150 MGY). Similar to the optimal solution of case study 1, these biorefinery plants are located in the counties with abundant feedstocks, to reduce the feedstock transportation cost, and most of them are near the Chicago area, which has the largest population in the state. The reason is that fuel ethanol has much higher transportation density and lower cost than cellulosic biomass feedstocks have. The two biorefineries located in Cook County and Will County are thermochemical conversion plants; the remaining plants use simultaneous saccharification and fermentation technology. The technology selection is driven by the feedstock availability: most feedstock resources in Cook County and Will County are wood residues, whereas in other counties agricultural residues such as corn stovers are the main sources. The "good choice" solution yields a slightly higher unit ethanol cost of $\$ 3.243 /$ gallon and an optimal production network with 10 biorefineries located in Cook County (150 MGY), DuPage County (150 MGY), Jo Daviess County (97 MGY), Bureau County (100 MGY), Iroquois County (60 MGY), Livingston County (105 MGY), Champaign County (48 MGY), Pike County (66 MGY), Saline County (53 MGY), and Union County (72 MGY). Although the capital cost increases as the number of plants increases, because of economy of scale, the total cost for feedstock transportation and fuel distribution is significantly reduced. Moreover, the shorter average transportation distance leads to a reduction of total GHG emissions, since road transportation is the major mode for shipping feedstocks and ethanol.

\section{[Figure 11]}

The total inventory level for all the feedstock sources in each month is given in Figure 12 . We can see a seasonal trend similar to the solution in case study 1 , because of 
the harvesting period of corn stovers. We note, however, that the maximum inventory level has reduced from around 6,000 tons in the previous case to around 3,000 tons in this case, although we are considering a scenario with much higher demand of cellulosic ethanol. The reduction of inventory results from the diversity of feedstock sources, as energy crops and wood chips, which have a larger harvesting window (some are perennial), do not need long-term storage, and can supply the biorefinery plants to maintain the continuous production.

\section{[Figure 12]}

Figure 13 shows the breakdown of the total cost for the "good choice" solution. The cost structure for this solution is similar to that of case study 1: the capital and production costs consist of more than two-thirds of the total cost; transportation cost is higher than the total cost for feedstock production, harvesting and storage. We note that the proportion for inventory cost is reduced because of the feedstock diversity. Although the unit ethanol production cost reduces compared to the previous case, feedstock cost still consists of $10 \%$ of the total cost. This is also because of feedstock diversity and the lower cost of energy crops and wood residues. The percentage of investment cost increases from $35 \%$ in the previous case to $39 \%$ in the current scenario, although this scenario has lower cellulosic ethanol cost. This is because large-scale production and transportation of cellulosic biomass requires more collection facilities and biorefinery plants, which have the maximum capacity limits.

\section{[Figure 13]}

For this case study we also addressed the tradeoff between the economic objective and the social objective. We again used the $\varepsilon$-constraint method to solve the bicriterion optimization problem and generate the Pareto curve given in Figure 14. The results show that as the total annualized cost increase from $\$ 5,333 \mathrm{MM}$ to $\$ 15,766 \mathrm{MM}$ and the total accrued jobs (full-time equivalent for one year) increase from around 121,152 to around 330,003 . The curve is almost linear, suggesting that the more money that is spent on the cellulosic biofuel supply chain, the more jobs it will create. This curve is consistent with the observation that investment in the displacement industries creates new job opportunities. The optimal numbers of biorefinery plants for each Pareto optimal solutions are also given Figure 14. We can see that as the total accrued local jobs 
increases, as the number of biorefineries plants increases. It implies that regional economy can benefit from building more cellulosic biorefinery plants, especially in the rural and less populated areas. We note a three-dimension Pareto surface can be obtained by solving the optimization problem with three objectives, but all the necessary insights can be obtained through the two Pareto curves in Figures 11 and 14, because the "best performance" of the social objective is almost proportional to the Pareto-optimal solution of the economic objective as shown in Figure 14. Therefore, a three-dimension Pareto surface is not considered for this case study.

\section{[Figure 14]}

\section{Remarks}

By comparing the results of case study 1 and case study 2, we can see that the minimum ethanol cost reduces from $\$ 3.663 /$ gal in case study 1 (near-term scenario) to $\$ 3.225$ in case study 2 (year 2022 scenario). The main reason is that case study 2 represents a scenario with large-scale production and consumption of cellulosic ethanol. The economy of scale and the shorter average transportation distances that reduce the total transportation cost are two major reasons. An additional reason is that increasing the feedstock diversity can hedge the seasonality, lower the inventory cost, and reduce deterioration amount.

The results of the two case studies have some similarities. For instance, biorefinery plants are usually located in the counties with abundant cellulosic biomass resources and are closer to the major demand center around Chicago area. Such facility location decisions are mainly due to the lower transportation density of cellulosic biomass sources and their high transportation costs. As can be seen from the cost breakdowns of the two case studies, the capital investment and production costs contribute around $70 \%$ of total cost. These results suggest that improving the conversion technologies is the key issue in overcome the barrier of commercializing cellulosic ethanol.

\section{Conclusions}

In this paper, we have developed an optimization approach for design and operations of cellulosic ethanol supply chains under economic, environmental, and social criteria. A multiperiod MILP model was developed that takes into account the main characteristics 
of cellulosic ethanol supply chains, such as seasonality of feedstock supply, biomass degradation with time, geographical diversity and availability of biomass resources, feedstock density, diverse conversion technologies and byproducts, infrastructure compatibility, demand distribution, regional economic condition, tax subsidies, and policy. Process models based on Aspen Plus for the conversion processes of potential feedstocks with possible biochemical and thermochemical pathways are linked to the MILP optimization model for detailed techno-economic and environmental performance analysis. The model also is integrated with LCA and EIO through a multiobjective optimization scheme to account for the economic, environmental, and social objectives. The MILP model simultaneously predicts the optimal network design, facility location, technology selection, capital investment, production operations, inventory control, and logistics management decisions. The multiobjective optimization problem is solved with an $\varepsilon$-constraint method, and the results reveal the tradeoffs among the economics, environmental impact, and social dimensions of the sustainable cellulosic biofuel supply chains. The proposed optimization approach is illustrated through two case studies for the county-level cellulosic ethanol supply chain for the state of Illinois. The results show that improving the conversion technologies is the key issue in overcoming the barrier of commercializing cellulosic ethanol and the maximum social impact of a cellulosic biofuel supply chain is almost proportional to its Pareto-optimal total annualized cost.

A possible future extension is to perform a nation-level case study that allows the biomass feedstocks and biofuels to be transported across the state borders. Due to the resulting large problem sizes for 3,141 counties in the U.S., efficient optimization algorithm and/or decomposition method are required for the nationwide analysis. Accounting for the time-dependent capacity expansion plans and the negotiation between biomass suppliers and biofuel producers could be another future research direction. Another future research direction is to consider the many types of uncertainty involved in the biofuels supply chain, such as ethanol demand fluctuation, biomass supply disruption, the emergence of more efficient conversion technologies, and changes of governmental incentives, etc. Investigating the impacts of different types of uncertainty and risks will be of significant importance to the design and operations of robust biofuels supply chains. 


\section{Acknowledgment}

This research is supported by the U.S. Department of Energy under contract DEAC02-06CH11357.

\section{Nomenclature}

\section{Sets/Indices}

$B \quad$ Set of biomass feedstocks indexed by $b$

$G \quad$ Set of byproducts of biomass conversion (e.g., solid waste, electricity, DDGS) indexed by $g$

I Set of harvesting sites indexed by $i$

$J \quad$ Set of collection facilities indexed by $j$

$K \quad$ Set of biorefineries indexed by $k$

$L \quad$ Set of demand zones indexed by $l$

$M \quad$ Set of transportation modes indexed by $m$

$P \quad$ Set of capacity levels of biorefineries indexed by $p$

$Q \quad$ Set of conversion technologies indexed by $q$

$R \quad$ Set of regional natural resources required for biofuel production indexed by $r$

$T \quad$ Set of time periods indexed by $t, t^{\prime}$

\section{Parameters}

$B A_{b, i, t} \quad$ Available amount of biomass type $b$ in harvesting site $i$ at time period $t(\mathrm{~kg})$

$B D_{b} \quad$ Density of dry biomass type $b\left(\mathrm{~kg} / \mathrm{m}^{3}\right)$

$B D W_{b} \quad$ Density of wet biomass type $b\left(\mathrm{~kg} / \mathrm{m}^{3}\right)$

$C B D_{b} \quad$ Unit cost of drying biomass type $b(\$ / \mathrm{kg})$

$C B P_{g, t} \quad$ Credit (negative value implies cost) of unit quantity of byproduct $g$ at time period $t(\$ / \mathrm{kg}$ or $\$ / \mathrm{kwh})$

$C F C_{j} \quad$ Fixed investment cost of installing collection facility $j(\$)$

$C P D_{b, q} \quad$ Variable production cost of unit quantity of biomass type $b$ with technology $q$ $(\$ / \mathrm{kg})$

$C R_{k, p, q} \quad$ Investment cost of installing biorefinery $k$ with capacity level $p$ and technology $q$

$C V C_{j} \quad$ Variable investment cost of installing collection facility $j\left(\$ / \mathrm{m}^{3}\right)$

$D E M_{l, t} \quad$ Demand of ethanol at demand zones $l$ at time period $t$ (gallon)

$D F C_{b, m} \quad$ Distance fixed cost of biomass type $b$ with transportation mode $m(\$ / \mathrm{kg})$

$D F C E_{m} \quad$ Distance fixed cost of ethanol with transportation mode $m$ (\$/gallon) 
$D S C R_{j, k, m}$ Distance from collection facility $j$ to biorefinery $k$ with transport mode $m$

$D S H C_{i, j, m}$ Distance from harvesting site $i$ to collection facility $j$ with transportation mode $m(\mathrm{~km})$

$D S H R_{i, k, m}$ Distance from harvesting site $i$ to biorefinery $k$ with transportation mode $m$ $(\mathrm{km})$

$D S R B_{k, l, m}$ Distance from biorefinery $k$ to demand zones $l$ with transportation mode $m$ $(\mathrm{km})$

$D V C_{b, m} \quad$ Distance variable cost of biomass type $b$ with transportation mode $m$ $(\$ / \mathrm{kg} / \mathrm{km})$

$D V C E_{m} \quad$ Distance variable cost of ethanol with transportation mode $m(\$ /$ gallon $/ \mathrm{km})$

$E B P_{g} \quad$ Emission credit from producing unit quantity of byproduct $g\left(\mathrm{~kg} \mathrm{CO}_{2}\right.$-eq/kwh)

$E D R_{b} \quad$ Emission of drying unit amount of biomass type $b\left(\mathrm{~kg} \mathrm{CO}_{2}\right.$-eq $/ \mathrm{kg}$ biomass $)$

$E E B D_{l} \quad$ Emission of blending and distributing unit amount of in demand zone $l(\mathrm{~kg}$ $\mathrm{CO}_{2}$-eq/gallon)

$E H V_{b, i} \quad$ Emission of cultivating and harvesting unit amount of biomass type $b$ from harvesting site $i\left(\mathrm{~kg} \mathrm{CO}_{2}\right.$-eq $/ \mathrm{kg}$ biomass)

$E I N V_{b, t} \quad$ Emission of storing unit amount of biomass type $b$ at time period $t\left(\mathrm{~kg} \mathrm{CO}_{2-}\right.$ eq/ kg biomass)

EINVE Emission of storing unit amount of ethanol ( $\mathrm{kg} \mathrm{CO}_{2}$-eq/gallon)

$E P D_{b, q} \quad$ Emission of converting unit amount of biomass type $b$ with technology $q(\mathrm{~kg}$ $\mathrm{CO}_{2}$-eq/ kg biomass)

$E T R B_{b, m} \quad$ Emission of transporting unit amount of biomass type $b$ for unit distance with transportation mode $m$ ( $\mathrm{kg} \mathrm{CO}_{2}$-eq $/ \mathrm{kg}$ biomass)

ETRE $_{m} \quad$ Emission of transporting unit amount of ethanol for unit distance with transportation mode $m$ ( $\mathrm{kg} \mathrm{CO}_{2}$-eq/gallon)

$F C P D_{k, p, q}$ Fixed production cost per unit capacity of biorefinery $k$ with capacity level $p$ and technology $q$ (\$/gallon)

$H_{t} \quad$ Duration of time period $t$ (day)

$H C B_{b, j, t} \quad$ Unit inventory holding cost of biomass type $b$ in collection facility $j$ at time period $t(\$ / \mathrm{kg})$

$H R B_{b, k} \quad$ Unit inventory holding cost of biomass type $b$ in biorefinery $k$ at time period $t$ $(\$ / \mathrm{kg})$

$H R E_{k} \quad$ Unit inventory holding cost of ethanol in biorefinery $k$ (\$/gallon)

$H_{R A T E} E_{b, i, t}$ Maximum harvesting rate of biomass type $b$ in harvesting site $i$ at time period $t$ ( $\mathrm{kg} /$ day) 
$H R V C_{b, i, t}$ Harvest and purchase cost of biomass type $b$ from harvesting site $i$ at time period $t(\$ / \mathrm{kg})$

$H Y \quad$ Production time duration of a year (day)

$I N C V O_{l} \quad$ Volumetric production incentive for ethanol blended in demand zone $l$ (\$/gallon)

$\operatorname{INCIM}_{k} \quad$ Maximum incentive that can be provided for the construction of biorefinery $k$ $(\$)$

$I N C I P_{k} \quad$ Maximum percentage of the construction cost of biorefinery $k$ that can be covered by incentive

IR Discount rate

$J B P_{g} \quad$ Number of accrued local jobs resulting from the unit economic credit from producing byproduct $g($ job $\cdot$ year $/ \$)$

$J C R_{p, q} \quad$ Number of accrued local jobs resulting from the investment of constructing biorefinery $k$ with capacity level $p$ and technology $q($ job·year $/ \$)$

$J D R_{b} \quad$ Number of accrued local jobs resulting from the unit expenditure of drying biomass type $b($ job $\cdot$ year $/ \$)$

JFC Number of accrued local jobs resulting from the unit expenditure of installing a collection facility (job·year/\$)

$J F P D_{p, q} \quad$ Number of accrued local jobs resulting from the unit expenditure of operating biorefinery with capacity level $p$ and technology $q$ (job·year $/ \$$ )

$J H V_{b} \quad$ Number of accrued local jobs resulting from the unit expenditure of cultivating and harvesting biomass type $b($ job $\cdot y e a r / \$)$

$J I N V_{b} \quad$ Number of accrued local jobs resulting from the unit expenditure of storing biomass type $b$ (job·year/\$)

JINVE Number of accrued local jobs resulting from the unit expenditure of storing unit amount of ethanol (job·year/\$)

$J P D_{b, q} \quad$ Number of accrued local jobs resulting from the unit expenditure of producing biomass type $b$ with technology $q$ (job·year $/ \$)$

$J T R B_{b, m} \quad$ Number of accrued local jobs resulting from the unit expenditure of transporting biomass type $b$ with transportation mode $m$ (job $\cdot$ year $/ \$$ )

$J T R E_{m} \quad$ Number of accrued local jobs resulting from the unit expenditure of transporting ethanol with mode $m$ (job·year $/ \$$ )

JVC Number of accrued local jobs resulting from the unit expenditure of adding storage capacity to a collection facility $(\mathrm{job} \cdot \mathrm{year} / \$)$

$M C_{b} \quad$ Moisture content of biomass type $b$

$M C D_{b} \quad$ Moisture content of dry biomass type $b$ 
$N R_{k, r, t} \quad$ Available amount of natural resource $r$ for biofuel production at biorefinery site $k$ in time period $t\left(\mathrm{~kg}\right.$ or $\left.\mathrm{m}^{3}\right)$

$N Y \quad$ Project lifetime in terms of years (year)

$P C_{j}^{L} \quad$ Lower bound of the capacity of collection facility $j$ if it is installed $\left(\mathrm{m}^{3}\right)$

$P C_{j}^{U} \quad$ Upper bound of the capacity of collection facility $j$ if it is installed $\left(\mathrm{m}^{3}\right)$

$P R_{p, q} \quad$ Upper bound of the capacity of biorefinery with capacity level $p$ and technology $q$ (gallon)

$T O R_{j} \quad$ Inventory turnover ratio of collecting facility $j$ ”

$V C C R_{j, k, m, t}$ Volume capacity for the transportation of biomass from collection facility $j$ to biorefinery $k$ with transportation mode $m$ at time period $t\left(\mathrm{~m}^{3}\right)$

$V_{C H C} C_{i, j, m, t}$ Volume capacity for the transportation of biomass from harvesting site $i$ to collection facility $j$ with transportation mode $m$ at time period $t\left(\mathrm{~m}^{3}\right)$

$V C H R_{i, k, m, t}$ Volume capacity for the transportation of biomass from harvesting site $i$ to biorefinery $k$ with transportation mode $m$ at time period $t\left(\mathrm{~m}^{3}\right)$

$W C C R_{j, k, m, t}$ Weight capacity for the transportation of biomass from collection facility $j$ to biorefinery $k$ with transportation mode $m$ in time period $t(\mathrm{~kg})$

$W C R B_{k, l, m, t}$ Weight capacity for the transportation of biomass biorefinery $k$ to demand zones $l$ with transportation mode $m$ in time period $t(\mathrm{~kg})$

$W C H C_{i, j, m, t}$ Weight capacity for the transportation of biomass from harvesting site $i$ to collection facility $j$ with transportation mode $m$ at time period $t(\mathrm{~kg})$

$W_{C H R_{i, k, m, t}}$ Weight capacity for the transportation of biomass from harvesting site $i$ to biorefinery $k$ with transportation mode $m$ in time period $t(\mathrm{~kg})$

$\alpha_{b, i, t} \quad$ Percentage of harvesting loss of biomass type $b$ in harvesting site $i$ at time period $t$

$\beta_{b, t} \quad$ Percentage of biomass type $b$ deteriorated in collection facility $j$ at time period $t$

$\eta_{b, q} \quad$ Conversion factor of biomass type $b$ with technology $q$ (gallon/kg)

$\rho_{b, q, r} \quad$ Required amount of natural resource $r$ for the conversion of unit quantity of biomass type $b$ with technology $q\left(\mathrm{~kg}\right.$ or $\left.\mathrm{m}^{3}\right)$

$\varepsilon_{b, g, q} \quad$ Amount of byproduct $g$ generated in the conversion of unit quantity of biomass type $b$ with technology $q$ (kg or kwh)

$\omega_{i, t} \quad$ Weather factor for biomass harvesting in site $i$ at time period $t$

$\theta_{q} \quad$ Minimum production amount as a percentage of capacity for biorefineries with technology $q$ 


\section{Integer Variables}

$x_{j} \quad 0-1$ variable, equal to 1 if a collection facility is located at site $j$

$y_{k, p, q} \quad 0-1$ variable, equal to 1 if a biorefinery $k$ with capacity level $p$ and technology $q$ is located at site $k$

\section{Continuous Variables (0 to $+\infty$ )}

$b_{b, j, t} \quad$ Inventory level of biomass type $b$ in collection facility $j$ at time period $t(\mathrm{~kg})$

$b_{b, k, t} \quad$ Inventory level of biomass type $b$ in biorefinery $k$ at time period $t(\mathrm{~kg})$

$\operatorname{cap}_{k, q} \quad$ Annual production capacity (in terms of ethanol) of biorefinery $k$ with technology $q$ (gallon)

capc $_{j} \quad$ Storage capacity of collection facility $j\left(\mathrm{~m}^{3}\right)$

$\operatorname{capr}_{k, p, q} \quad$ Annual production capacity (in terms of ethanol) of biorefinery $k$ with capacity level $p$ and technology $q$ (gallon)

eir $r_{k, t} \quad$ Inventory level of ethanol in biorefinery $k$ at time period $t$ (gallon)

$f c r_{b, j, k, m, t}$ Amount of biomass type $b$ shipped from collection facility $j$ to biorefinery $k$ with transportation mode $m$ in time period $t(\mathrm{~kg})$

$f h c_{b, i, j, m, t}$ Amount of biomass type $b$ shipped from harvesting site $i$ to collection facility $j$ with transportation mode $m$ in time period $t(\mathrm{~kg})$

$f h r_{b, i, k, m, t} \quad$ Amount of biomass type $b$ shipped from harvesting site $i$ to biorefinery $k$ with transportation mode $m$ in time period $t(\mathrm{~kg})$

$f r b_{k, l, m, t} \quad$ Amount of ethanol shipped from biorefinery $k$ to demand zones $l$ with transportation mode $m$ in time period $t$ (gallon)

$\operatorname{harv}_{b, i, t} \quad$ Amount of biomass type $b$ in harvested from harvesting site $i$ in time period $t$ $(\mathrm{kg})$

inci $i_{k} \quad$ Incentive received for the construction of biorefinery $k(\$)$

tc Total annualized cost of operating the biofuel supply chain (\$)

tcapc $_{j} \quad$ Total cost of installing collection facility $j(\$)$

tcapr $_{k} \quad$ Total cost of installing biorefinery $k(\$)$

$t c b d_{b, t} \quad$ Total cost of drying biomass type $b$ at time period $t$

$t c b p_{g, t} \quad$ Total credit of byproduct $g$ produced at time period $t$

$\operatorname{tcin}_{b, t} \quad$ Total inventory cost of biomass type $b$ at time period $t$

tcine $e_{t}$ Total inventory cost of ethanol at time period $t$

$t_{c p d} \quad$ Total annual production cost in biorefinery $k$

$t c p h b_{b, t} \quad$ Total cost of purchasing and harvesting biomass type $b$ at time period $t$ 


$\begin{array}{ll}t c t r_{b, m, t} & \text { Total cost of shipping biomass type } b \text { with transportation mode } m \text { in time } \\ & \text { period } t \\ t c t r e_{m, t} & \text { Total cost of transporting ethanol with transportation mode } m \text { in time period } t \\ t e & \text { Total GHG emission }\left(\mathrm{CO}_{2} \text {-equiv/year) of operating the biofuel supply chain }\right. \\ & (\mathrm{kg}) \\ & \text { Total accrued local jobs (full-time equivalent for one year) through the } \\ & \text { lifetime of the biofuel supply chain } \\ w & \text { Amount of biomass type } b \text { used for the production of biofuels through } \\ w b_{b, k, q, t} & \text { technology } q \text { in biorefinery } k \text { at time period } t\left(\mathrm{~m}^{3}\right) \\ w b p_{g, k, t} & \text { Amount of byproduct } g \text { generated in biorefinery } k \text { at time period } t \text { (kg or kwh) } \\ w e_{k, q, t} & \text { Amount of ethanol produced through technology } q \text { in biorefinery } k \text { at time } \\ & \text { period } t \text { (gallon) }\end{array}$

\section{References}

1. Dalgaard T, Jørgensen U, Olesen JE, Jensen ES, Kristensen ES. Looking at Biofuels and Bioenergy. Science. 2006; 312:1743 - 1744.

2. Rostrup-Nielsen JR. Making Fuels from Biomass. Science. 2005; 308:1421-1422.

3. U.S. Energy Information Administration. http://www.eia.doe.gov/ (October 1, 2010),

4. Energy Independence and Security Act of 2007. In RL34294, P.L. 110-140 ed.; 2007; Vol. H.R. 6.

5. Biomass Program Multi-Year Program Plan 2010; U.S. Department of Energy: Office of Energy Efficiency and Renewable Energy: 2007.

6. National Biofuels Action Plan; Biomass Research and Development Board: U.S. Department of Agriculture and U.S. Department of Energy: 2008.

7. Shah N. Process industry supply chains: Advances and challenges. Computers \& Chemical Engineering. 2005; 29:1225-1236.

8. Papageorgiou LG. Supply chain optimisation for the process industries: Advances and opportunities. Computers \& Chemical Engineering. 2009; 32:1931-1938.

9. Towler GP, Oroskar AR, Smith SE. Development of a Sustainable Liquid Fuels Infrastructure Based on Biomass. Environmental Progress. 2004; 23:334-341.

10. Dunnett A, Adjiman C, Shah N. Biomass to Heat Supply Chains: Applications of Process Optimisation. Process Safety and Environmental Protection. 2007; 85:419-429.

11. Dunnett AJ, Adjiman CS, Shah N. A spatially explicit whole-system model of the lignocellulosic bioethanol supply chain: an assessment of decentralised processing potential. Biotechnology for Biofuels. 2008; 1:13.

12. Zamboni A, Shah N, Bezzo F. Spatially Explicit Static Model for the Strategic Design of Future Bioethanol Production Systems. 1. Cost Minimization. Energy \& Fuels. 2009; 23:5121-5133.

13. Eksioglu SD, Acharya A, Leightley LE, Arora S. Analyzing the design and management of biomass-to-biorefinery supply chain. Computers \& Industrial Engineering. 2009; 57:1342-1352. 
14. Huang Y, Chen C-W, Fan Y. Multistage optimization of the supply chains of biofuels. Transportation Research Part E. 2010; In press.

15. Mansoornejad B, Chambost V, Stuart P. Integrating product portfolio design and supply chain design for the forest biorefinery. Computers and Chemical Engineering. 2010; In press.

16. Dal Mas M, Giarola S, Zamboni A, Bezzo F. Capacity Planning and Financial Optimisation of the Bioethanol Supply Chain Under Price Uncertainty. Computer Aided Chemical Engineering. 2010; 28:97-102.

17. Kim J, Realff MJ, Lee JH, Whittaker C, Furtner L. Design of biomass processing network for biofuel production using an MILP model. Biomass and Bioenergy. 2010; In press.

18. Aksoy B, Cullinan H, Webster D, Gue K, Sukumaran S, Eden M, Jrd NS. Woody Biomass and Mill Waste Utilization Opportunities in Alabama: Transportation Cost Minimization, Optimum Facility Location, Economic Feasibility, and Impact. Environmental Progress \& Sustainable Energy. 2010; In press.

19. Corsano G, Vecchietti AR, Montagna JM. Optimal design for sustainable bioethanol supply chain considering detailed plant performance model. Computers \& Chemical Engineering. 2011; In press.

20. Akgul O, Zamboni A, Bezzo F, Shah N, Papageorgiou LG. Optimization-Based Approaches for Bioethanol Supply Chains. Industrial \& Engineering Chemistry Research. 2010; In press.

21. Bojarski AD, Laínez JM, Espuña A, Puigjaner L. Incorporating environmental impacts and regulations in a holistic supply chains modeling: An LCA approach. Computers \& Chemical Engineering. 2009; 33:1747-1759.

22. Grossmann IE, Guillén-Gosálbez G. Scope for the application of mathematical programming techniques in the synthesis and planning of sustainable processes. Computers \& Chemical Engineering. 2010; 34:1365-1376.

23. You F, Grossmann IE. Design of responsive supply chains under demand uncertainty. Computers \& Chemical Engineering. 2008; 32:3090-3111.

24. You F, Grossmann IE. Balancing responsiveness and economics in the design of process supply chains with multi-echelon stochastic inventory. AIChE Journal. 2011; 57:178-192.

25. Georgiadis MC, Pistikopoulos EN. An integrated framework for robust and flexible process systems. Industrial \& Engineering Chemistry Research. 1999; 38:133-143.

26. Guillén G, Mele F, Bagajewicz M, Espuña A, Puigjaner L. Multiobjective supply chain design under uncertainty. CHemical Engineering Science. 2005; 60:1535-1553.

27. You F, Wassick JM, Grossmann IE. Risk management for global supply chain planning under uncertainty: models and algorithms. AIChE Journal. 2009; 55:931-946.

28. Zamboni A, Bezzo F, Shah N. Spatially Explicit Static Model for the Strategic Design of Future Bioethanol Production Systems. 2. Multi-Objective Environmental Optimization. Energy \& Fuels. 2009; 23:5134-5143.

29. Mele FD, Gonzalo Guillén-Gosálbez, Jiménez L. Optimal Planning of Supply Chains for Bioethanol and Sugar Production with Economic and Environmental Concerns. Computer Aided Chemical Engineering. 2009; 26:997-1002.

30. You F, Wang B. Life Cycle Optimization of Biomass-to-Liquids Supply Chains with Distributed-Centralized Processing Networks. Industrial \& Engineering Chemistry 
Research. 2011; Submitted.

31. Elia JA, Baliban RC, Xiao X, Floudas CA. Optimal energy supply network determination and life cycle analysis for hybrid coal, biomass and natural gas to liquid (CBGTL) plants using carbon-based hydrogen production. 2010; Submitted.

32. Hamelinck CN, Hooijdonk Gv, Faaij AP. Ethanol from lignocellulosic biomass: techno-economic performance in short-, middle- and long-term. Biomass and Bioenergy. 2005; 28:384-410.

33. Martin M, Ahmetovic E, Grossmann IE. Optimization of Water Consumption in Second Generation Bioethanol Plants. Industrial \& Engineering Chemistry Research. 2011; In press:doi: 10.1021/ie101175p.

34. Wu M, Mintz M, Wang M, Arora S Consumptive water use in the production of ethanol and petroleum gasoline; Argonne National Laboratory: 2009.

35. Aden A. Water Usage for Current and Future Ethanol Production. Southwest Hydrology. 2007; September/October:22-23.

36. Aspen Plus ${ }^{\mathrm{TM}}$. Aspen Technology: Cambridge, MA, 2006.

37. Aden A, Ruth M, Ibsen K, Jechura J, Neeves K, Sheehan J, Wallace R Lignocellulosic biomass to ethanol process design and economics utilizing co-current dilute acid prehydrolysis and enzymatic hydrolysis for corn stover; NREL report NREL/TP-51032438: 2002.

38. Phillips SA, A.; Jechura, J.; Dayton, D. . Thermochemical ethanol via indirect gasification and mixed alcohol synthesis of lignocellulosic biomass.; National Renewable Energy Laboratory, Golden CO, 2007.

39. Foust TD, Aden A, Dutta A, Phillips S. An economic and environmental comparison of a biochemical and a thermochemical lignocellulosic ethanol conversion processes. Cellulose. 2009; 16:547-565.

40. Farrell AE, Plevin RJ, Turner BT, Jones AD, O'Hare M, Kammen DM. Ethanol Can Contribute to Energy and Environmental Goals. Science 2006; 311:506-508

41. Argonne GREET Model. http://greet.es.anl.gov/ (October 1, 2010),

42. U.S. Life Cycle Inventory Database. http://www.nrel.gov/lci/ (October 1, 2010),

43. PRe-Consultants The Eco-indicator 99, A damage oriented method for life cycle impact assessment. Methodology Report and Manual for Designers; Amersfoort, Netherlands, 2000.

44. Job and Economic Development Impact Model. http://www.nrel.gov/analysis/jedi/ (October 1, 2010),

45. Miller RE, Blair. PD. Input-Output Analysis: Foundations and Extensions. Cambridge University Press: 2009.

46. Minnesota IMPLAN Group. http://www.implan.com/

47. You F, Pinto JM, Grossmann IE, Megan L. Optimal distribution-inventory planning of industrial gases: II. MINLP models and algorithms for stochastic cases. Industrial \& Engineering Chemistry Research. 2011; 50:2928-2945.

48. You F, Grossmann IE. Stochastic inventory management for tactical process planning under uncertainties: MINLP model and algorithms. AIChE Journal. 2010; In press:DOI: 10.1002/aic. 12338 .

49. You F, Grossmann IE. Integrated multi-echelon supply chain design with inventories under uncertainty: MINLP models, computational strategies. AIChE Journal. 2010; $56: 419$ - 440 . 
50. You F, Grossmann IE. Mixed-integer nonlinear programming models and algorithms for large-scale supply chain design with stochastic inventory management. Industrial \& Engineering Chemistry Research. 2008; 47: 7802-7817.

51. Rentizelas AA, Tolis AJ, Tatsiopoulos IP. Logistics issues of biomass: The storage problem and the multi-biomass supply chain. Renewable and Sustainable Energy Reviews. 2009; 13:887-894.

52. 2009 Biomass Program Overview; U.S. Department of Energy: 2009.

53. Google Maps http://map.google.com/

54. Searcy E, Flynn P, Ghafoori E, Kumar AA. The Relative Cost of Biomass Energy Transport. Applied Biochemistry and Biotechnology. 2007; 136-140:639-652.

55. Mahmud H, Flynn PC. Rail vs Truck Transport of Biomass. Applied Biochemistry and Biotechnology. 2006; 129-132:88-103.

56. National Agricultural Statistics Service. http://www.nass.usda.gov/ (October 1, 2010), 57. Petrolia DR. The economics of harvesting and transporting corn stover for conversion to fuel ethanol: A case study for Minnesota. Biomass and Bioenergy. 2008; 32:603-612.

58. U. S. Census Bureau. http://www.census.gov/ (October 1, 2010),

59. Biomass as Feedstock for a Bioenergy and Bioproducts Industry: The Technical Feasibility of a Billion-Ton Annual Supply; U.S. Department of Agriculture and U.S. Department of Energy: 2005. 


\title{
Appendix
}

\section{Table A1. Technoeconomic analysis results for 45 MGY ethanol productions with simultaneous saccharification and fermentation technology}

\author{
Dilute Acid Prehydrolysis with Saccharification and Co-Fermentation \\ Ethanol Production (MM Gal. / Year) 45.0 \\ Ethanol Yield (Gal / Dry US Ton Feedstock) 89.7
}

\begin{tabular}{lrrrr}
\multicolumn{1}{c}{ Capital Costs } & & & \multicolumn{2}{c}{ Operating Costs (cents/gal ethanol) } \\
\cline { 1 - 1 } Feed Handling & $\$ 0$ & & Feedstock & 51.2 \\
Pretreatment & $\$ 17,500,000$ & & Biomass to Boiler & 0.0 \\
Neutralization/Conditioning & $\$ 7,200,000$ & & CSL & 3.1 \\
Saccharification \& Fermentation & $\$ 7,800,000$ & & Cellulase & 9.7 \\
Distillation and Solids Recovery & $\$ 19,000,000$ & & Other Raw Materials & 11.1 \\
Wastewater Treatment & $\$ 2,700,000$ & & Waste Disposal & 1.5 \\
Storage & $\$ 2,000,000$ & & Electricity & -6.8 \\
Boiler/Turbogenerator & $\$ 31,600,000$ & & Fixed Costs & 15.6 \\
$\quad$ Utilities & $\$ 4,200,000$ & & Capital Depreciation & 17.8 \\
Total Installed Equipment Cost & $\$ 91,900,000$ & & Average Income Tax & 13.2 \\
Added Costs & $\$ 67,500,000$ & & Average Return on & 31.7 \\
$\quad$ (\% of TPI) & $42 \%$ & &
\end{tabular}


Table A2. Emission analysis results for 45 MGY ethanol productions with simultaneous saccharification and fermentation technology

\begin{tabular}{|c|c|c|c|}
\hline & \multicolumn{2}{|l|}{ Vapor } & \multirow{2}{*}{$\begin{array}{l}\text { Solids } \\
809 \\
\end{array}$} \\
\hline & 550 & 810 & \\
\hline & $\begin{array}{ll}\text { Scrubbed } & \text { Fermentation } \\
\text { Offgas } & \\
\end{array}$ & Flue Gas & Boiler Ash \\
\hline Temperature $\left({ }^{\circ} \mathrm{C}\right)$ & 29 & 200 & \\
\hline Pressure (atm) & 1 & 1 & \\
\hline Mole Flow $(\mathrm{kmol} / \mathrm{hr})$ & 365 & 9512 & \\
\hline Mass Flow $(\mathrm{kg} / \mathrm{hr})$ & 15604 & 255496 & \\
\hline Volume Flow (1/min) & 167265 & 6361890 & \\
\hline Enthalpy (MMBtu/hr) & -132 & -1041 & \\
\hline \multicolumn{4}{|c|}{ Mass Flow $(\mathrm{kg} / \mathrm{hr}) \quad(8,406 \mathrm{hr} /$ year $)$} \\
\hline ETHANOL & 4 & 0 & \\
\hline $\mathrm{H}_{2} \mathrm{O}$ & 281 & 54985 & \\
\hline $\mathrm{H}_{2} \mathrm{SO}_{4}$ & 0 & 50 & \\
\hline $\mathrm{N} 2$ & 0 & 145172 & \\
\hline $\mathrm{CO}_{2}$ & 15191 & 43765 & \\
\hline $\mathrm{CH}_{4}$ & & 2 & \\
\hline $\mathrm{NO}_{2}$ & & 40 & \\
\hline $\mathrm{SO}_{2}$ & & 3263 & \\
\hline $\mathrm{CO}$ & & 40 & \\
\hline Ash & & & 2801 \\
\hline
\end{tabular}


Table A3. Technoeconomic analysis) results for 45 MMgal ethanol productions with thermochemical conversion technology

BCL Gasifier, Tar Reformer, Sulfur Removal, MoS2 Catalyst, Fuel Purification, Steam-Power Cycle EtOH Production at Operating Capacity (MM Gal / year) 45.0 EtOH Product Yield (gal / Dry US Ton Feedstock) 80.1 Mixed Alcohols Production at Operating Capacity (MM Gal / year) $\quad 52.8$

Mixed Alcohols Product Yield (gal / Dry US Ton Feedstock) 94.1

Feed Handling \& Drying

Gasification

Tar Reforming \& Quench

Acid Gas \& Sulfur Removal

Alcohol Synthesis - Compression

Alcohol Synthesis - Other

Alcohol Separation

Steam System \& Power Generation

Cooling Water \& Other Utilities

Total Installed Equipment Cost

Indirect Costs

( $\%$ of TPI)

Project Contingency

Total Project Investment (TPI)

$\$ 20,200,000$
$\$ 11,600,000$
$\$ 33,600,000$
$\$ 12,700,000$
$\$ 13,600,000$
$\$ 4,300,000$
$\$ 6,400,000$
$\$ 14,800,000$

$\$ 3,300,000$
$\$ 120,500,000$
$47,100,000$
$28.1 \%$
$3,600,000$
$\$ 167,600,000$

Operating Costs (cents/gal product)

\begin{tabular}{lr}
\hline Feedstock & 57.4 \\
Natural Gas & 0.0 \\
Catalysts & 0.3 \\
Olivine & 0.7 \\
Other Raw Materials & 1.6 \\
Waste Disposal & 0.5 \\
Electricity & 0.0 \\
Fixed Costs & 24.3 \\
& - \\
Co-product credits & 20.7 \\
Capital Depreciation & 18.7 \\
Average Income Tax & 14.2 \\
Average Return on Investment & 34.4 \\
&
\end{tabular}


Table A4. Emission analysis results for 45 MGY ethanol productions with thermochemical conversion technology

\begin{tabular}{|l|l|l|l|l|l|}
\hline & Sand/Ash & Sulfur & Wastewater & $\begin{array}{l}\mathrm{CO}_{2} \\
\text { vent }\end{array}$ & Flue Gas \\
\hline \multicolumn{2}{|l|}{ Mass flow (kg/hr) (8,406 hr/year) } & \multicolumn{5}{l|}{} \\
\hline $\mathrm{N}_{2}$ & & & & & 175771 \\
\hline $\mathrm{O}_{2}$ & & & & & 8011 \\
\hline Argon & & & & & 2997 \\
\hline Water & 80 & & 385 & & 84436 \\
\hline $\mathrm{CO}_{2}$ & & & & 17423 & 59072 \\
\hline $\mathrm{SO}_{2}$ & & & & & 38 \\
\hline $\mathrm{NO}_{2}$ & & & & & 89 \\
\hline Ash & 559 & & & & \\
\hline Olivine & 164 & & & & \\
\hline Sulfur (solid) & & 36 & & & \\
\hline Stream & 219 & 324 & 305 & 357 & 112 \\
\hline
\end{tabular}




\section{List of Figure Captions}

Figure 1. Optimal design and operations of regional cellulosic biofuel supply chain.

Figure 2. Cellulosic biofuel supply chain superstructure.

Figure 3. Process flow diagram of biochemical conversion technology. ${ }^{39}$

Figure 4. Process flow diagram of thermochemical conversion technology. ${ }^{39}$

Figure 5. Integration of life cycle assessment with multiobjective optimization.

Figure 6. Spatial distribution of cellulosic biomass resources and the population density of the state of Illinois.

Figure 7. Cost-effective design of cellulosic biofuel supply chain of Illinois for the nearterm scenario.

Figure 8. Total inventory of feedstocks in each month for case study 1.

Figure 9. Cost breakdown for case study 1.

Figure 10. Pareto curve showing tradeoff between economic and environmental performances of cellulosic biofuel supply chains for case study 2 .

Figure 11. Optimal design of cellulosic biofuel supply chain for case study 2 (minimum cost solution and the "good choice" solution).

Figure 12. Total inventory of feedstocks in each month for the "good choice" solution in case study 2 .

Figure 13. Cost breakdown for the "good choice" solution in case study 2.

Figure 14. Pareto curve showing tradeoff between economic and social performances for case study 2 (numbers blow the dots are for the optimal number of biorefinery plants to be installed in each Pareto curve solution). 

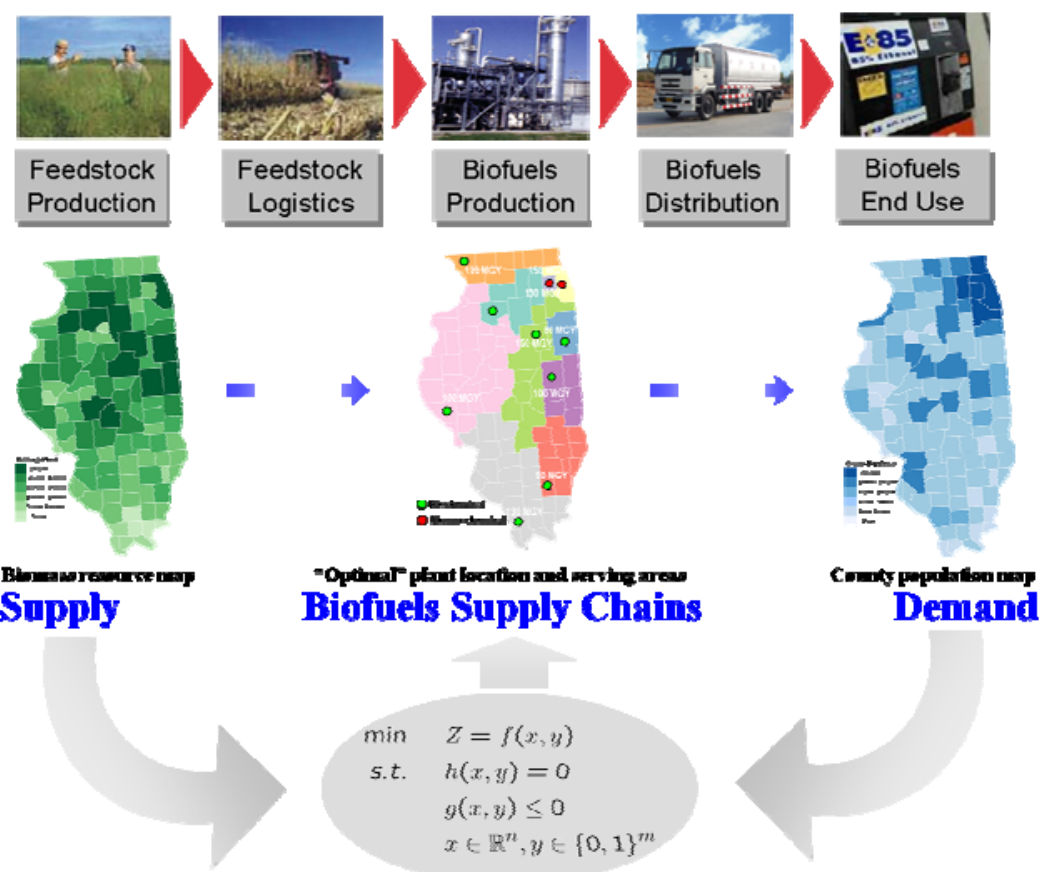

Optimination Models \& Agorithms

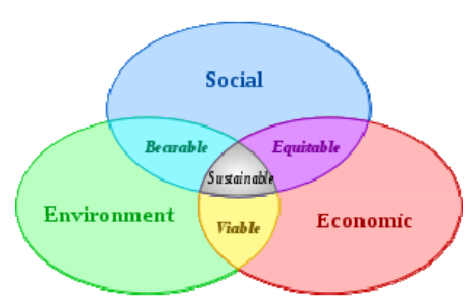

Figure 1. Optimal design and operations of regional cellulosic biofuel supply chain 


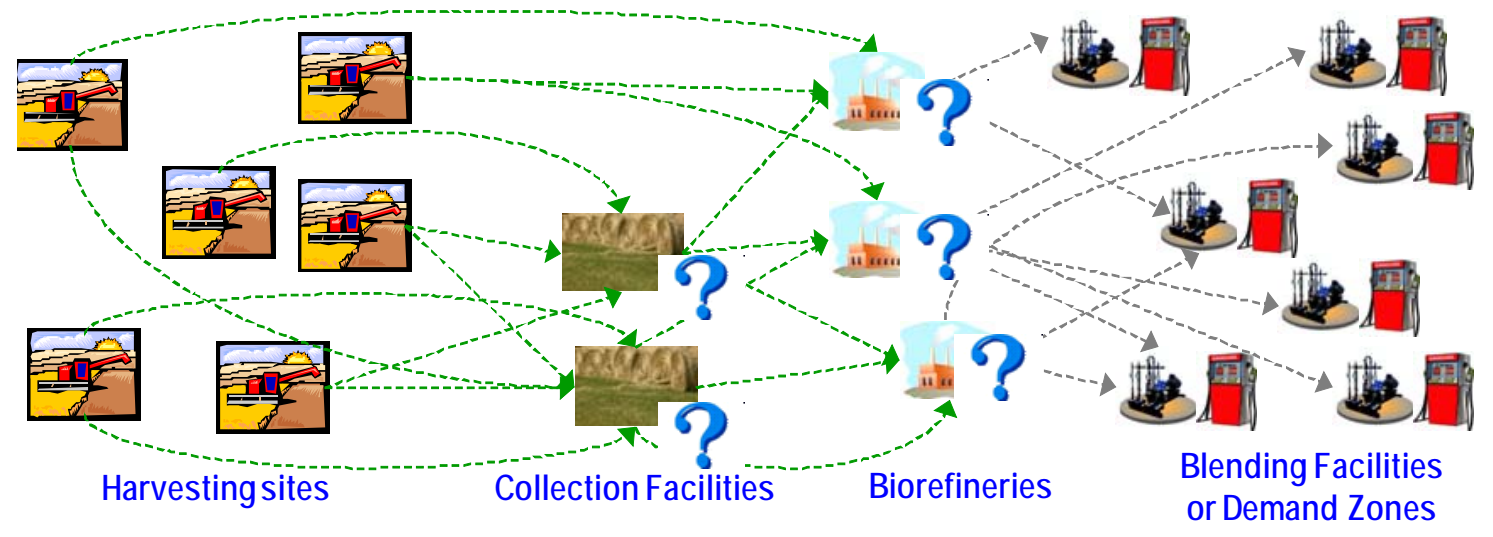

Figure 2. Cellulosic biofuel supply chain superstructure 


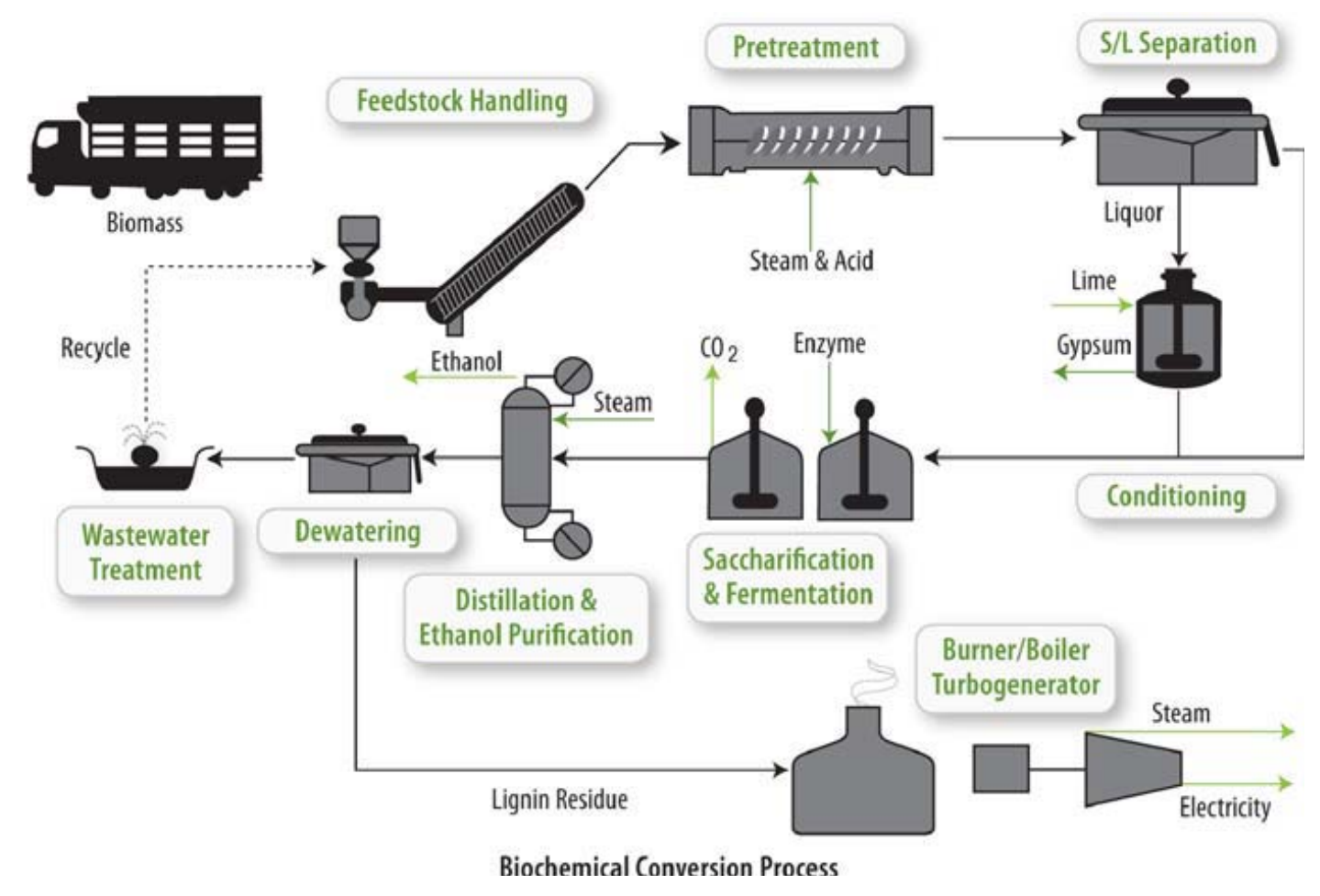

Figure 3. Process flow diagram of biochemical conversion technology. ${ }^{39}$ 


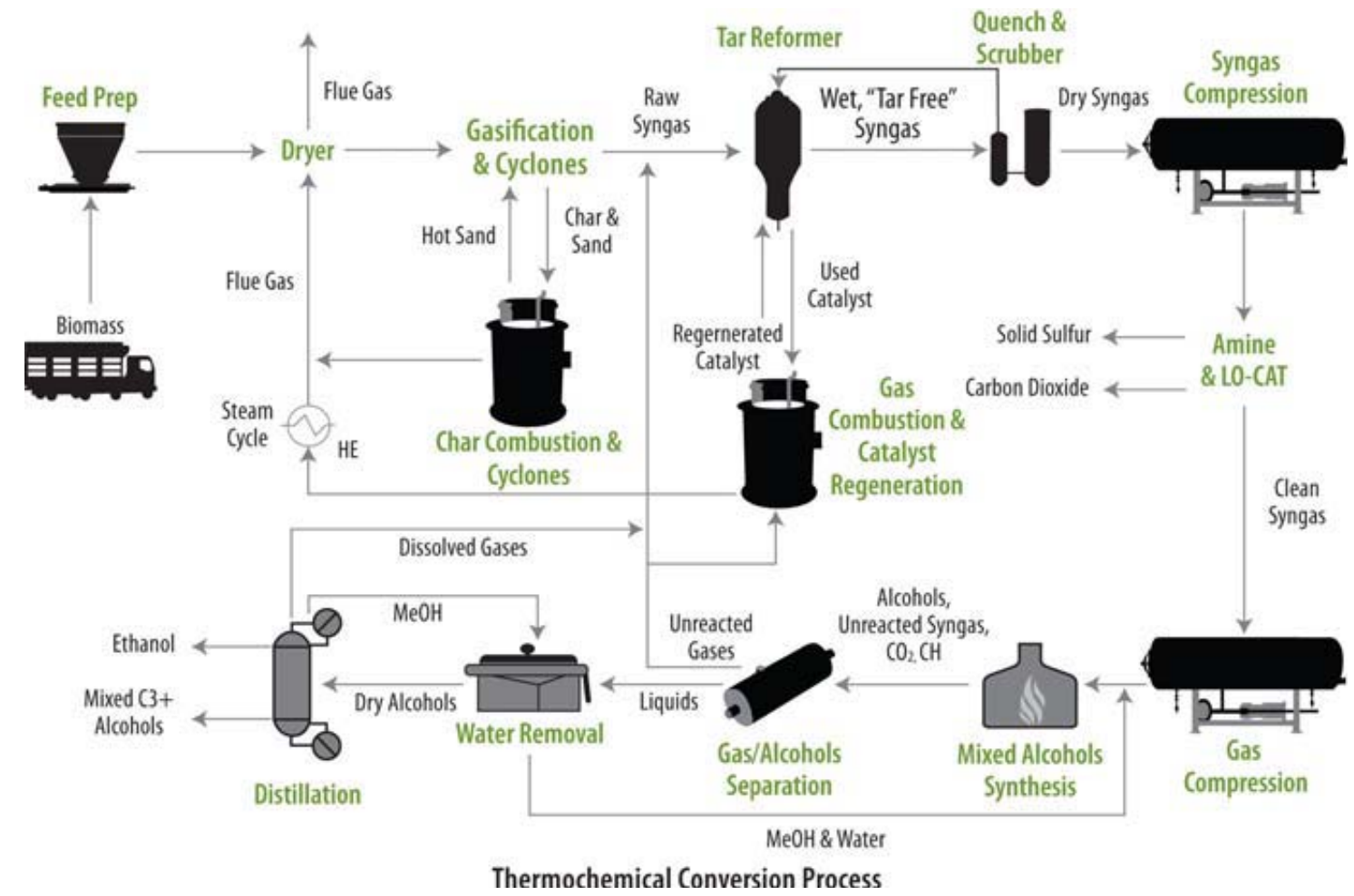

Figure 4. Process flow diagram of thermochemical conversion technology ${ }^{39}$ 

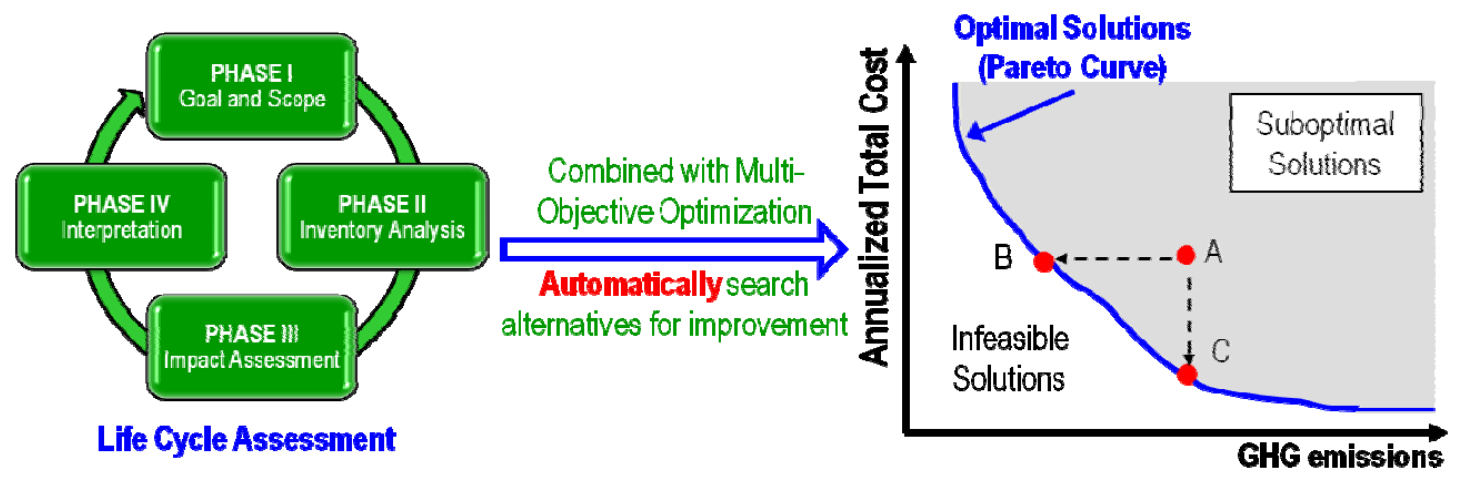

Figure 5. Integration of life cycle assessment with multiobjective optimization 


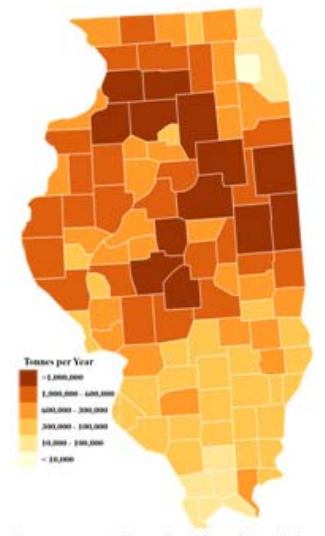

Resource of agricultural residue

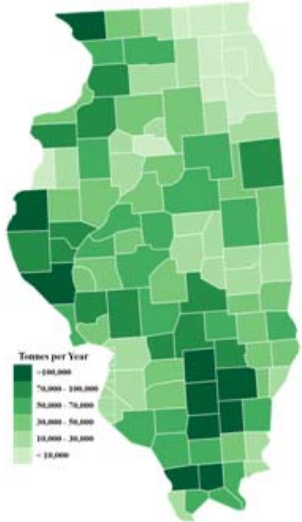

Resource of energy crop
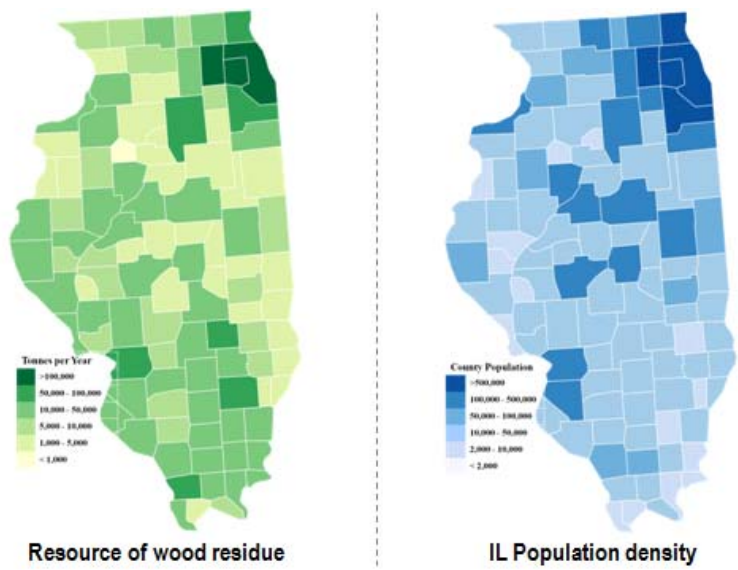

IL Population density

Figure 6. Spatial distribution of cellulosic biomass resources and the population density of the state of Illinois 


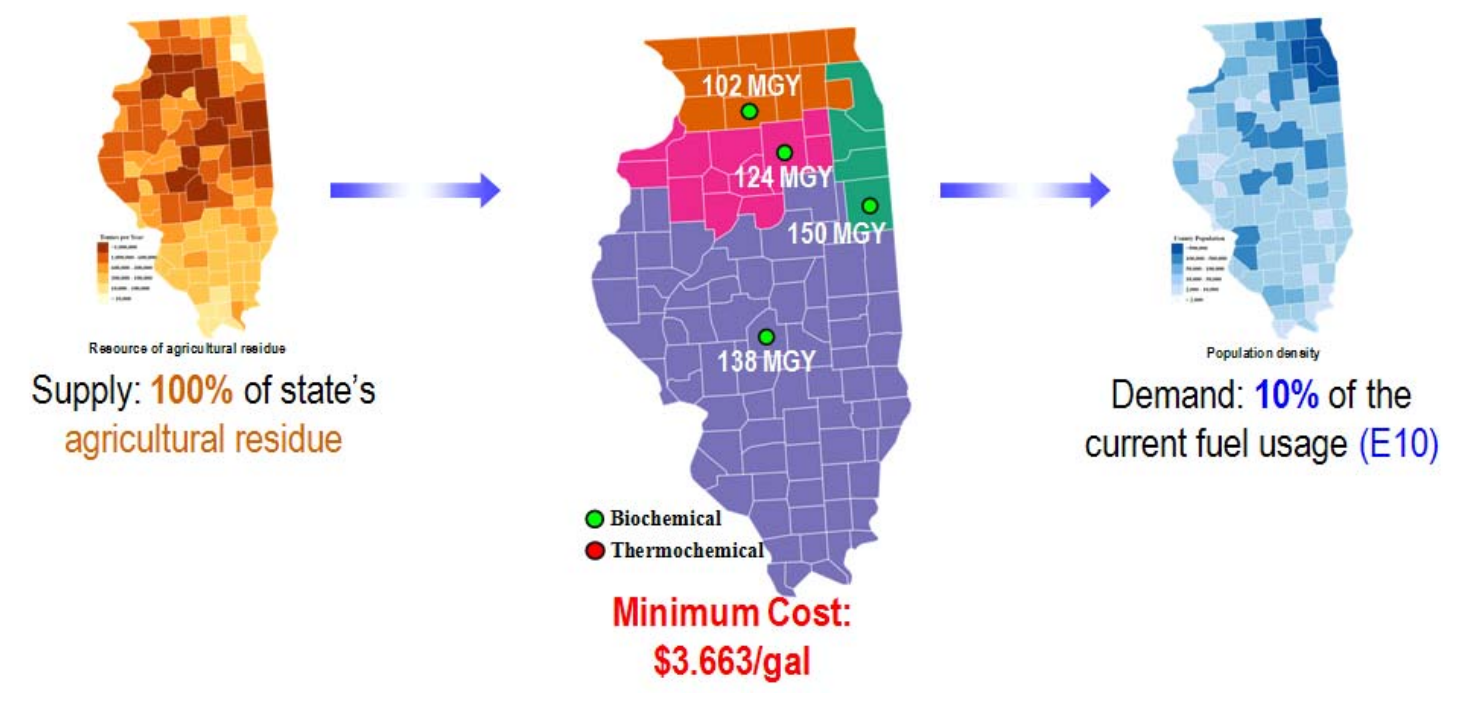

Figure 7. Cost-effective design of cellulosic biofuel supply chain of Illinois for the near-term scenario 


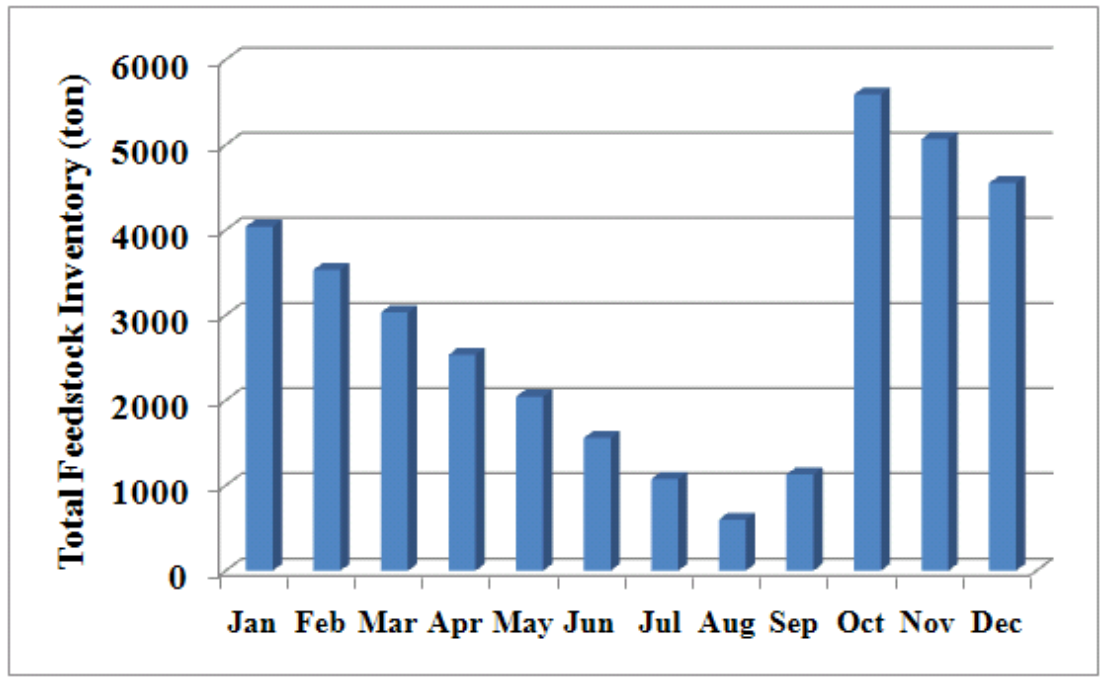

Figure 8. Total inventory of feedstocks in each month for case study 1 


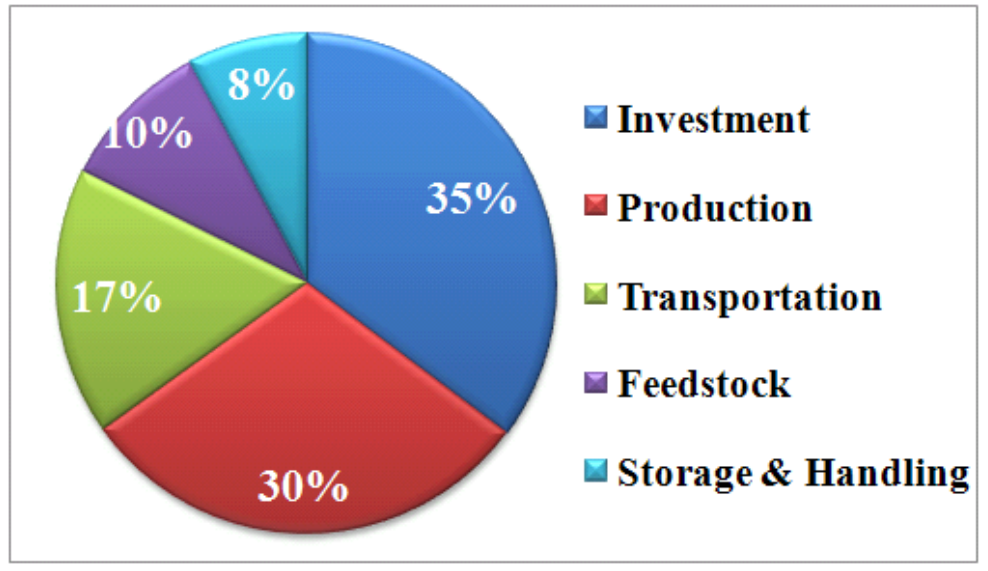

Figure 9. Cost breakdown for case study 1 


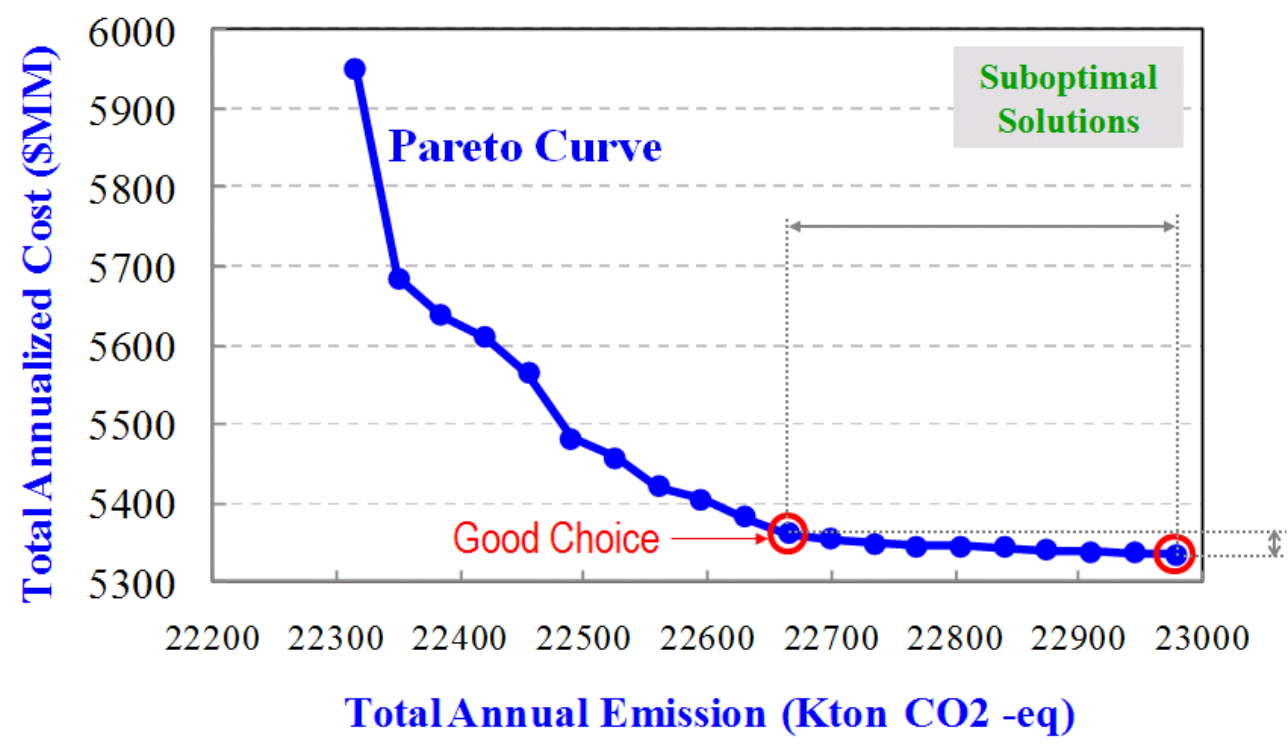

Figure 10. Pareto curve showing tradeoff between economic and environmental performances of cellulosic biofuel supply chains for case study 2 


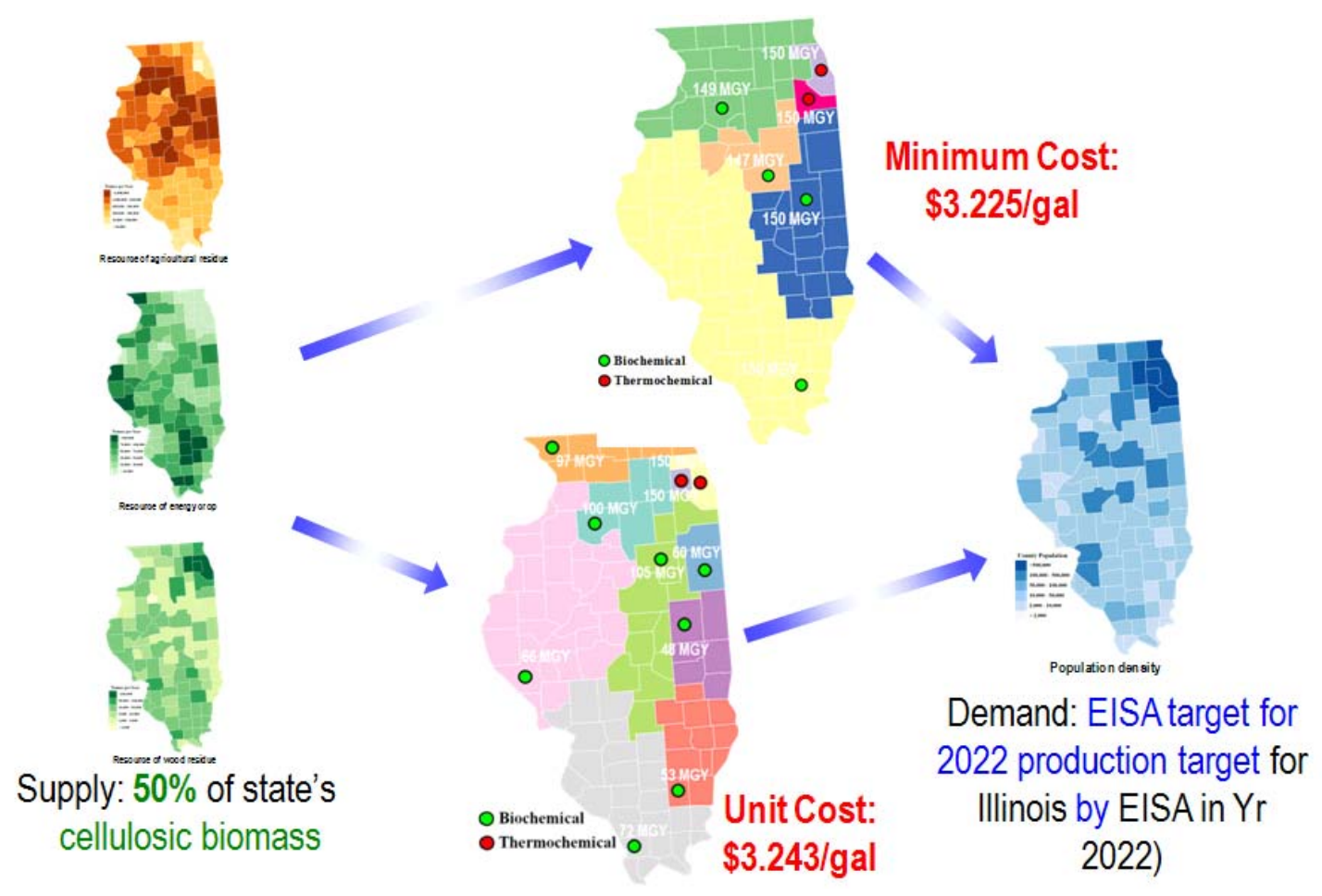

Figure 11. Optimal design of cellulosic biofuel supply chain for case study 2 (minimum cost solution and the "good choice" solution) 


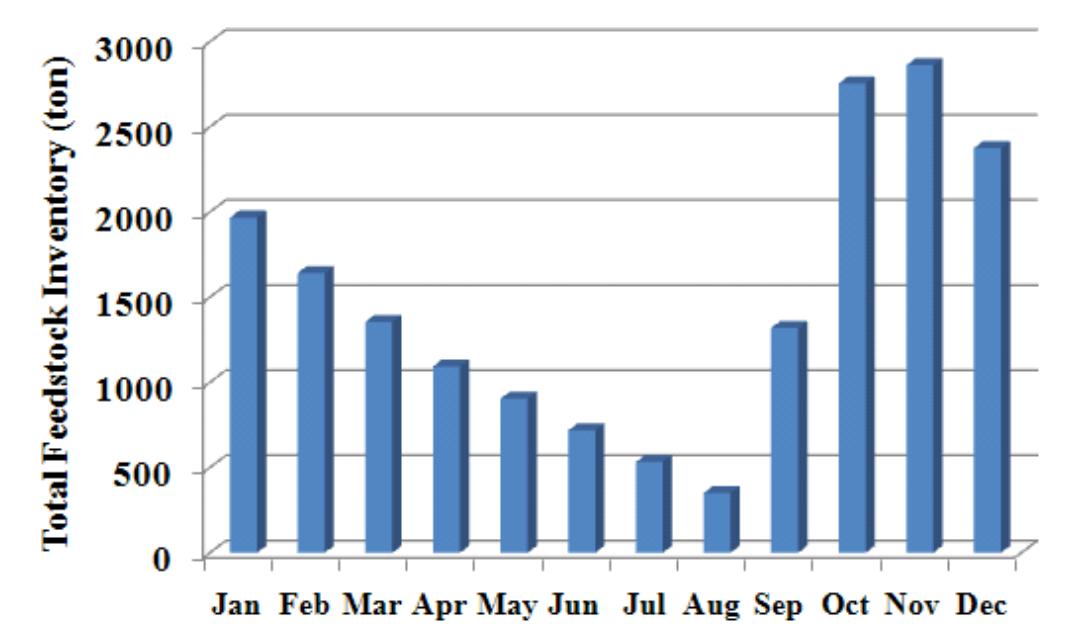

Figure 12. Total inventory of feedstocks in each month for the "good choice" solution in case study 2 


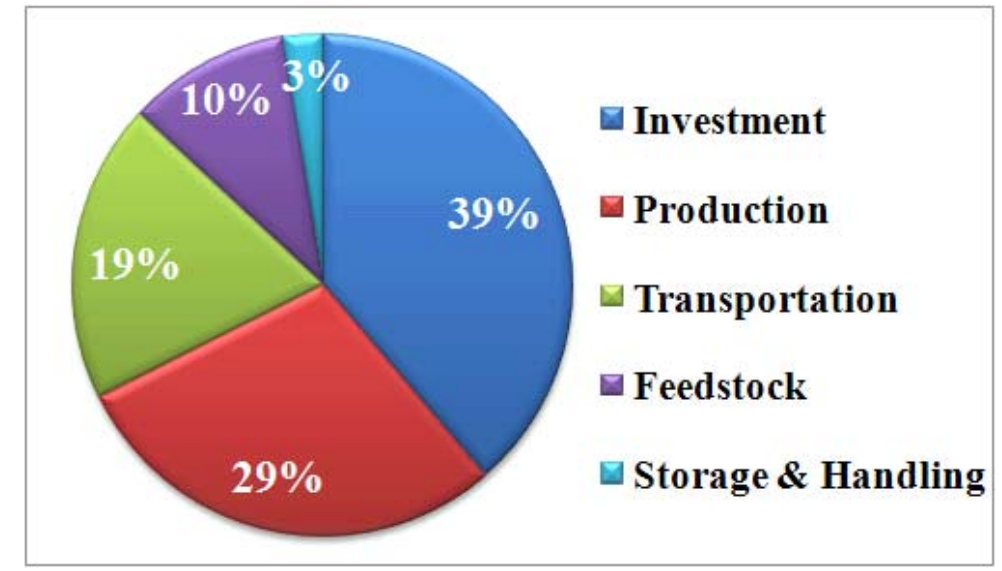

Figure 13. Cost breakdown for the "good choice" solution in case study 2 


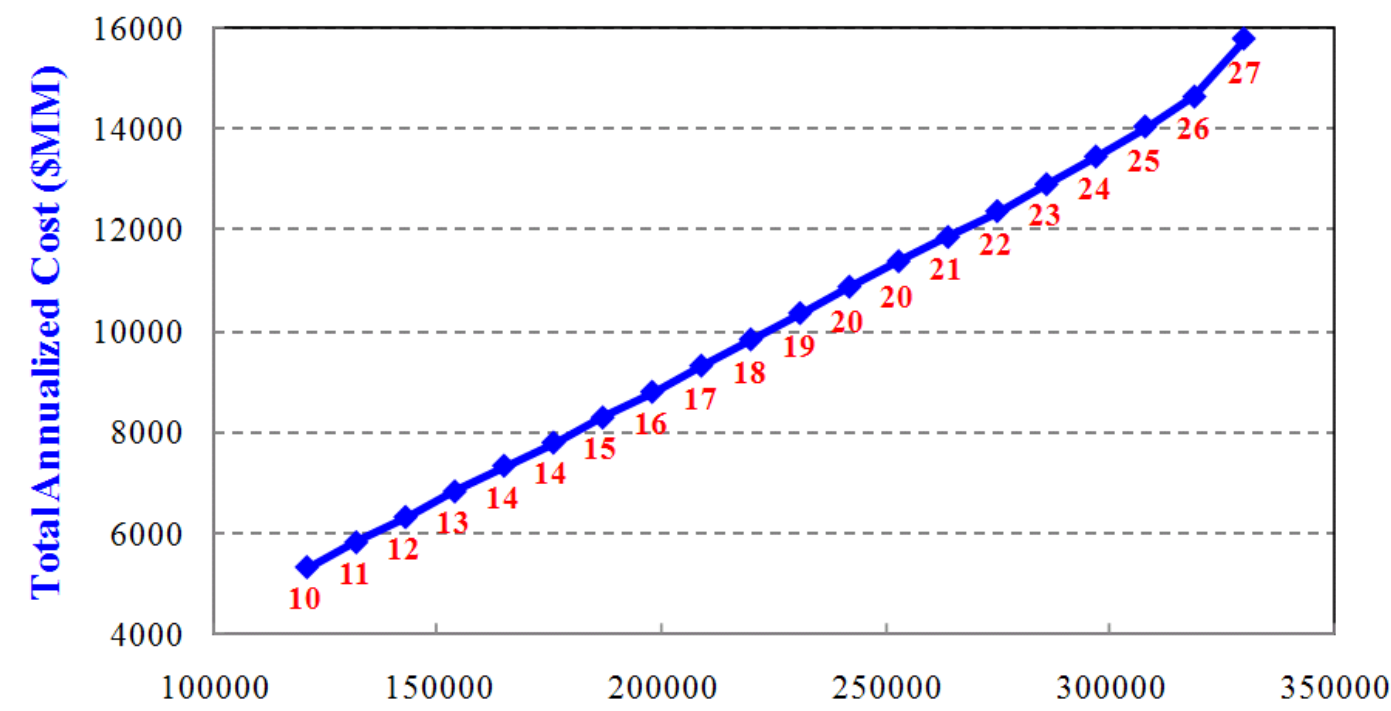

TotalAccrued Local Job (full time equivalent for a year)

Figure 14. Pareto curve showing tradeoff between economic and social performances for case study 2 (numbers blow the dots are for the optimal number of biorefinery plants to be installed in each Pareto curve solution) 